\title{
Article
}

\section{Prediction and Simulator Verification of Roll/Lateral Adverse Aeroservoelastic Rotorcraft-Pilot Couplings}

Muscarello, Vincenzo, Quaranta, Giuseppe, Masarati, Pierangelo and Lu, Linghai

Available at https://clok.uclan.ac.uk/13907/

Muscarello, Vincenzo, Quaranta, Giuseppe, Masarati, Pierangelo and Lu, Linghai orcid iconORCID: 0000-0002-2688-7944 (2015) Prediction and

Simulator Verification of Roll/Lateral Adverse Aeroservoelastic Rotorcraft-Pilot Couplings. Journal of guidance, control and dynamics, 39 (1). pp. 1-12. ISSN 0731-5090

It is advisable to refer to the publisher's version if you intend to cite from the work. http://dx.doi.org/10.2514/1.G001121

For more information about UCLan's research in this area go to

http://www.uclan.ac.uk/researchgroups/ and search for <name of research Group>.

For information about Research generally at UCLan please go to http://www.uclan.ac.uk/research/

All outputs in CLoK are protected by Intellectual Property Rights law, including Copyright law. Copyright, IPR and Moral Rights for the works on this site are retained by the individual authors and/or other copyright owners. Terms and conditions for use of this material are defined in the policies page. 


\title{
Prediction and Simulator Verification of Roll/Lateral Adverse Aeroservoelastic Rotorcraft-Pilot Couplings
}

\author{
Vincenzo Muscarello,, Giuseppe Quaranta,, \pm and Pierangelo Masarati \\ Politecnico di Milano, 20156 Milan, Italy \\ and \\ Linghai Lu, $\underline{\S}$ Michael Jones, $\mathbb{I}$ and Michael Jump** \\ University of Liverpool, Liverpool, England L69 3BX, United Kingdom
}

DOI: $10.2514 / 1 . G 001121$

\begin{abstract}
The involuntary interaction of a pilot with an aircraft can be described as pilot-assisted oscillations. Such phenomena are usually only addressed late in the design process when they manifest themselves during ground/flight testing. Methods to be able to predict such phenomena as early as possible are therefore useful. This work describes a technique to predict the adverse aeroservoelastic rotorcraft-pilot couplings, specifically between a rotorcraft's roll motion and the resultant involuntary pilot lateral cyclic motion. By coupling linear vehicle aeroservoelastic models and experimentally identified pilot biodynamic models, pilot-assisted oscillations and no-pilot-assisted oscillation conditions have been numerically predicted for a soft-in-plane hingeless helicopter with a lightly damped regressive lead-lag mode that strongly interacts with the roll mode at a frequency within the biodynamic band of the pilots. These predictions have then been verified using real-time flight-simulation experiments. The absence of any similar adverse couplings experienced while using only rigid-body models in the flight simulator verified that the observed phenomena were indeed aeroelastic in nature. The excellent agreement between the numerical predictions and the observed experimental results indicates that the techniques developed in this paper can be used to highlight the proneness of new or existing designs to pilot-assisted oscillations.
\end{abstract}

\section{Nomenclature}

$a_{Y}^{\text {seat }}$
$C_{\zeta}$

$G_{1 c}$

$G_{Y}$

$H(s, \boldsymbol{p})$

$H_{P P}(s)$

$H_{S}$

$H_{U}$

$H_{\text {WO }}$

$K_{p}$

$K_{q}$

$K_{r}$

$K_{\zeta}$ $\mathrm{N} \cdot \mathrm{m} \cdot \mathrm{s} \cdot \mathrm{rad}^{-1}$ $\mathrm{m} \cdot \mathrm{s}^{-2} \cdot \mathrm{rad}^{-1}$ $\mathrm{s}^{2} \cdot \mathrm{m}^{-1}$

$=$ stable portion of $H$

$=$ unstable portion of $H$ system gain, $\mathrm{s}$ system gain, $\mathrm{s}$ system gain, $\mathrm{s}$
$=$ lateral acceleration at the pilot's seat, $\mathrm{m} \cdot \mathrm{s}^{-2}$

$=$ equivalent lead-lag angular damping,

$=$ gearing ratio between lateral cyclic stick percent displacement and blade pitch rotation, deg /\%

$=$ loop transfer function gain

$=$ vehicle transfer function between lateral cyclic pitch and lateral acceleration at pilot's seat,

$=$ structural pilot model transfer function, $\%$

$=$ flight-simulator washout filter transfer function

$=$ roll rate stability and control augmentation

$=$ pitch rate stability and control augmentation

$=$ yaw rate stability and control augmentation

$=$ equivalent lead-lag angular stiffness,

Received 19 October 2014; revision received 13 January 2015; accepted for publication 17 January 2015; published online 24 March 2015. Copyright $(\underset{)}{ }$ 2015 by Pierangelo Masarati. Published by the American Institute of Aeronautics and Astronautics, Inc., with permission. Copies of this paper may be made for personal or internal use, on condition that the copier pay the $\$ 10.00$ per-copy fee to the Copyright Clearance Center, Inc., 222 Rosewood Drive, Danvers, MA 01923; include the code 1533-3884/15 and \$10.00 in correspondence with the CCC.

*Research Assistant, Dipartimento di Scienze e Tecnologie Aerospaziali.

${ }^{\dagger}$ Assistant Professor, Dipartimento di Scienze e Tecnologie Aerospaziali.

${ }^{\ddagger}$ Associate Professor, Dipartimento di Scienze e Tecnologie Aerospaziali. Member AIAA.

${ }^{\S}$ Research Associate, School of Engineering, Flight Science and Technology. Member AIAA.

TPh.D. Candidate, School of Engineering, Flight Science and Technology; currently, DLR, Germany Aerospace Center, 38108 Brunswick, Germany.

**Senior Lecturer, School of Engineering, Flight Science and Technology.

\begin{tabular}{|c|c|c|}
\hline$K_{\vartheta}$ & $=$ & $\begin{array}{l}\text { pitch angle stability and control augmentation } \\
\text { system gain }\end{array}$ \\
\hline$K_{\varphi}$ & $=$ & $\begin{array}{l}\text { roll angle stability and control augmentation } \\
\text { system gain }\end{array}$ \\
\hline$K_{\psi}$ & $=$ & $\begin{array}{l}\text { yaw angle stability and control augmentation } \\
\text { system gain }\end{array}$ \\
\hline $\operatorname{LTF}(s, \boldsymbol{p})$ & $=$ & $\begin{array}{l}\text { predicted seat lateral acceleration loop transfer } \\
\text { function }\end{array}$ \\
\hline $\operatorname{LTF}_{\text {sim }}(s, \boldsymbol{p})$ & $=$ & $\begin{array}{l}\text { flight-simulator seat lateral acceleration loop } \\
\text { transfer function }\end{array}$ \\
\hline$p$ & $=$ & roll rate, $\mathrm{rad} \cdot \mathrm{s}^{-1}$ \\
\hline$p$ & $=$ & vector of trim parameters \\
\hline$Q_{\zeta}$ & $=$ & equivalent moment about lead-lag hinge, $\mathrm{N} \cdot \mathrm{m}$ \\
\hline$q$ & $=$ & pitch rate, $\mathrm{rad} \cdot \mathrm{s}^{-1}$ \\
\hline$R$ & $=$ & main rotor radius, $\mathrm{m}$ \\
\hline$r$ & $=$ & yaw rate, $\mathrm{rad} \cdot \mathrm{s}^{-1}$ \\
\hline$T_{p}$ & $=$ & structural pilot model real pole time constant, $\mathrm{s}$ \\
\hline & $=$ & structural pilot model zero time constant, st \\
\hline$V_{\max }$ & $=$ & maximum horizontal flight speed, kt \\
\hline$V_{\infty}$ & $=$ & airstream velocity, kt \\
\hline$W_{\mathrm{TO}}$ & $=$ & takeoff weight, $\mathrm{N}$ \\
\hline$x_{\mathrm{CM}}$ & $=$ & center of mass longitudinal location, $\mathrm{m}$ \\
\hline$Y_{T}$ & $=$ & tail rotor thrust, $\mathrm{N}$ \\
\hline$Y_{T v}$ & $=$ & $\begin{array}{l}\text { tail rotor thrust-lateral velocity control deriva- } \\
\text { tive, } \mathrm{N} \cdot \mathrm{s} \cdot \mathrm{m}^{-1}\end{array}$ \\
\hline$Y_{T \theta_{P}}$ & $=$ & $\begin{array}{l}\text { tail rotor thrust-collective pitch control deriva- } \\
\text { tive, } \mathrm{N} \cdot \mathrm{rad}^{-1}\end{array}$ \\
\hline$\gamma$ & $=$ & main rotor Lock number \\
\hline$\delta_{Y}$ & $=$ & lateral cyclic stick rotation, $\%$ \\
\hline$\zeta$ & $=$ & blade lead-lag rotation, rad \\
\hline$\vartheta$ & $=$ & pitch angle, rad \\
\hline$\theta_{1 c}$ & $=$ & lateral cyclic pitch, rad \\
\hline$\theta_{P}$ & $=$ & tail rotor collective pitch, rad \\
\hline$\mu_{P}$ & $=$ & structural pilot model gain, $\mathrm{s}^{2} \cdot \mathrm{m}^{-1}$ \\
\hline$\nu_{\beta}$ & $=$ & main rotor nondimensional flap frequency \\
\hline$\nu_{\zeta}$ & $=$ & main rotor nondimensional lag frequency \\
\hline$\xi$ & $=$ & $\begin{array}{l}\text { structural pilot model complex poles damping } \\
\text { factor }\end{array}$ \\
\hline$\sigma$ & $=$ & main rotor solidity \\
\hline$\tau_{e}$ & $=$ & effective time delay, $\mathrm{s}$ \\
\hline
\end{tabular}




$\begin{array}{lll}\tau_{\text {lead }} & =\begin{array}{l}\text { lead introduced in loop transfer function by } \\ \text { washout filter, } \mathrm{s}\end{array} \\ \tau_{\text {sim }} & \text { time delay on seat lateral acceleration transfer } \\ & \text { function introduced by flight simulator, } \mathrm{s} \\ \tau_{Y} & \text { nominal loop transfer function time delay, } \mathrm{s} \\ \Phi_{(\cdot)}(\omega) & = & \text { power spectral density of signal }(\cdot) \\ \varphi & = & \text { roll angle, rad } \\ \psi & = & \text { yaw angle, rad } \\ \Omega & = & \text { main rotor angular velocity, rad } \cdot \mathrm{s}^{-1} \\ \omega_{n} & = & \text { structural pilot model complex poles frequency, } \\ & & \text { rad } \cdot \mathrm{s}^{-1}\end{array}$

\section{Introduction}

$\mathbf{E}$ VEN after more than 110 years of manned heavier-than-air aviation, and despite significant investigative efforts, aircraft/ rotorcraft-pilot couplings (A/RPCs) still manifest themselves within current air vehicle operations. The history of aviation records a significant number of occurrences of critical pilot-vehicle interactions $[1,2]$. All of these were undesirable, many were adverse, and some of them were fatal.

During A/RPC phenomena, the pilot, potentially as a consequence of misleading or incorrectly interpreted cues, makes control inceptor inputs that result in inadvertent or unintentional commands. These commands, in turn, may produce a vehicle behavior that causes further misleading cues, inducing additional adverse inputs. Given the correct set of circumstances, this coupling of pilot and vehicle dynamics can become unstable.

The most widely known and commonly investigated types of A/ RPC are pilot-induced oscillations (PIOs). PIO phenomena have been recorded since the very first powered flight attempts by the Wright brothers [3]. The name refers to an oscillatory behavior of the vehicle that results from commands intentionally introduced by the pilot as a result of misinterpreted or contradictory vehicle response cues. As such, PIOs mostly occur in the frequency band specific to the discipline of flight mechanics, the upper limit of which corresponds to the cutoff frequency of the human operator (conventionally set to about $1 \mathrm{~Hz}$ in [4]).

Another well-known type of A/RPC, of a slightly different nature, is the pilot-assisted oscillation, or pilot-augmented oscillation (PAO). In this case, the pilot's intervention is involuntary; it is generally the result of cockpit vibrations or other vehicle accelerations into the control inceptors through the pilot's limbs (this phenomenon is often termed biodynamic feedthrough (BDFT); see, for example, [5]). The frequency band that characterizes the phenomenon is above that of PIO, as the pilot is no longer capable of intentionally producing commands to compensate for the undesired motion, but below an upper limit related to the biodynamics of the neuromuscular system and the dynamics of the control device (conventionally set to about $8 \mathrm{~Hz}$ in [4]). At higher frequencies, the biomechanical response of the human body is expected to filter out any excitation originating from the motion of the cockpit. This paper investigates the development of modeling and simulation techniques, coupling real-time PAO-prone aeroservoelastic rotorcraft models with pilot models to predict the occurrence of PAO-prone vehicle configurations and to then verify these predictions using piloted flight simulation.

PIO and PAO phenomena have been extensively analyzed in fixedwing aircraft, primarily only when they have been unexpectedly encountered in flight. The situation is similar for rotary-wing aircraft, although the number of reported events and studies is rather more limited. With respect to PAOs, in 1968, Gabel and Wilson [6] discussed the problem of external slung load instabilities, considering the case of vertical bounce of the slung load interacting with the pilot through the collective control system. Collective bounce, a PAO phenomenon specific to rotorcraft, is a vertical oscillation of the helicopter, caused by a pulsating thrust induced by an oscillation involuntarily introduced by the pilot using the collective control. In 2007, Walden [2] presented an extensive discussion of aeromechanical instabilities that occurred on several rotorcraft during their development and acceptance by the U.S. Navy, including the CH-46,
UH-60, SH-60, CH-53, V-22, and AH-1. The history of tiltrotor development also contains many PAO events, from the early design and testing of the XV-15 technology demonstrator [7] to several instances of aeroservoelastic pilot-in-the-loop coupling encountered during the testing of the V-22 [8]. A reasonably complete database of $\mathrm{PIO}$ and PAO incidents that have occurred to fixed- and rotary-wing aircraft is reported in [9]. Most of those events occurred in the PAO frequency band and involved the involuntary participation of the pilot, often interacting with the automatic flight control system (AFCS). In many examples, any attempt to reduce the vehicle's PAO tendency was conducted on a case-by-case basis, and it was usually addressed by procedural mitigations. Planned structural interventions were either deferred or canceled due to a lack of time or resources.

In recent years, the interest in rotorcraft-pilot couplings (RPCs) has received considerable attention. In Europe, the GARTEUR Helicopter Action Group 16 (HC AG-16) [4] and the European Commission 7th Framework Programme project titled "Aircraft and Rotorcraft Pilot Couplings-Tools and Techniques for Alleviation and Detection” or ARISTOTEL +10 [10,11,9], addressed this topic.

With respect to aeroelastic $\overline{\mathrm{RP}} \overline{\mathrm{C}}(\mathrm{PAO})$, the focus of HC AG-16 was to further understand collective bounce. In [12], Gennaretti et al. discussed occurrences of this phenomenon and investigated it numerically, identifying the influencing factors and the modeling requirements for its simulation. Within ARISTOTEL, a closed-loop aeroelastic experiment involving collective bounce was presented and discussed by Masarati et al. in [13]. In [14], Muscarello et al. pinpointed the phase margin reduction introduced by the main rotor coning mode in the collective pitch-heave loop transfer function as the key factor in the manifestation of collective bounce.

In the present work, the focus on rotorcraft PAO phenomena moved from the heave to the roll axis, which mainly involves the lateral cyclic control. Aeroelastic (i.e., relatively high-frequency coupling between longitudinal and lateral cyclic controls and the corresponding rotorcraft surge) and sway motions appear to be less critical than heave. Changes in cyclic pitch do not cause an immediate horizontal force imbalance but rather additional pitch/roll moments. These are usually filtered by the low-pass behavior of rotorcraft rotors, particularly articulated ones. As a consequence, these couplings are usually somewhat less prone to causing further inadvertent pilot inputs to the controls, although Walden [2] reported that the lateral axis also tends to be critical for PAOs. Many of the problems discussed in [2] arise because of deficiencies in the flight control system (FCS) design where the possibility of indirect pilot activity from other axes contributing to instability in the control law's primary axis has not been considered in an appropriate manner.

Examples of PAO occurrences about the lateral axis reported in [2] involved a "shuffle mode oscillation" on the CH-46D/E Sea Knight, where the PAO resulted from an aeromechanical instability created by the lightly damped main rotor regressive lead-lag mode and the pilot's lateral cyclic stick coupling through the stability augmentation system (SAS). Similarly, a lateral PAO was uncovered on the SH-60B Seahawk, caused by a coupling of the $3.0 \mathrm{~Hz}$ onground roll mode with the main rotor system's regressive lead-lag mode. This resulted in limit-cycle oscillations while the aircraft was on the ground. The coupling was associated with large aft rotor flapping, which created insufficient rotor lead-lag damping as well as pilot-SAS interaction. Several mishaps have also been reported for the CH-53E Super Stallion with external loads. PAOs were determined to be the result of uncommanded pilot inputs interacting with the first vertical and lateral fuselage bending modes through the AFCS.

For the rigid-body PIO case, rotorcraft are more prone to RPCs than their fixed-wing counterparts because their rigid-body mode stability margins are reduced compared to fixed-wing aircraft (often, the phugoid and the Dutch roll modes are intrinsically unstable and require a stability augmentation system), and because they are required to fulfill difficult and high-workload missions. For the aeroelastic PAO case, it is recognized that pilot biomechanical responses

\footnotetext{
${ }^{\dagger}$ Information available online at http://www.aristotel.progressima.eu/ [retrieved December 2014].
} 
are task dependent (see, for example, [15] for a detailed discussion); later in this work, it is shown that high-gain tasks may reduce the stability margin of the coupled pilot-vehicle system (PVS) about the roll axis. It is well known that high gain tasks can cause rigid-body RPCs, but it is expected that high-gain tasks will also act as PAO triggers. The typical pilot's biomechanical frequency range $(2-8 \mathrm{~Hz})$ overlaps with that of flexible airframe, rotor, FCS/AFCS, actuator dynamics, and drive train dynamics modes of vibration, leaving rotorcraft vulnerable to a variety of aeroservoelastic instabilities $[\underline{4}, \underline{16}]$.

In this work, PAO phenomena associated with the roll axis are investigated using two aeroservoelastic helicopter simulation models representative of the IAR S.A. Braçov IAR330 Puma (formerly Sud Aviation, and now Airbus Helicopters) and of the MesserschmittBölkow-Blohm (now Airbus Helicopters) BO105. Although these helicopters are not known to be PAO prone, they have been chosen because the required aeroelastic data are available from the open literature. To predict PAO tendencies, the involuntary control loop is closed using biodynamic feedthrough data acquired from trained test pilots by performing dedicated biodynamic tests. The PAO predictions are then verified in a flight simulator using the same test pilots and aeroservoelastic models to simulate the PVS.

This paper will show how it is possible to predict lateral PAOs of rotorcraft using experimentally identified BDFT transfer functions of the pilots. The predictions will be compared with the results of an experimental campaign performed in the flight simulator of the University of Liverpool. The results of the numerical models and those of flight simulations are in good agreement. Additionally, the experimental campaign highlighted the crucial role of fully detailed aeroservoelastic models with the pilot in the loop to confirm the numerical prediction. In fact, real-time capable numerical simulation models containing sufficient high-frequency modal information had to be developed for this study.

The paper proceeds as follows. Section II describes the dynamic setup of the two helicopters used for lateral PAO investigations and the tests used to identify the biodynamic feedthrough of the pilots, and it presents the results of the bioaeroservoelastic tions. Section III discusses the piloted flight-simulation tests used to confirm the predictions: the test course of the selected maneuver, the effect of the flight-simulator washout filter on the aeroelastic model dynamics, and, finally, the results of the tests. Section IV brings the paper to a close by drawing conclusions to the work performed.

\section{Prediction of Aeroservoelastic Roll Instabilities with Pilot in the Loop}

This section briefly describes the preparation of the aeroservoelastic helicopter models and the identification of the pilot biomechanical feedthrough models that are subsequently used to predict the stability of the bioaeroservoelastic system about the roll axis.

\section{A. Aeroservoelastic Helicopter Models}

The linearized aeroservoelastic models of the helicopters have been prepared using the simulation tool MASST (Modern Aeroservoelastic State Space Tools), developed at Politecnico di Milano for the aeroservoelastic and aeromechanical analysis of aircraft and rotorcraft $[17,18]$. MASST analyzes compact yet complete modular models of complex linearized aeroservoelastic systems. The models are composed of subcomponents collected from well-known, reliable, and possibly state-of-the-art sources and blended together in a mathematical environment.

The problem is formulated in state-space form. The equations of motion of the system are cast as first-order time differential equations. As a consequence, generic state-space approaches can be used to analyze aeroelastic systems.

\footnotetext{
$\$$ The term "bioaeroservoelasticity" is used to indicate the multidisciplinary analysis of a vehicle encompassing not only aerodynamics, structural dynamics, and control system dynamics (as in aeroservoelasticity) but also the biodynamics of the pilot that closes an involuntary control loop.
}

MASST has been designed to be modular and to incorporate heterogeneous subcomponents from different sources to allow models to be built that include deformable aircraft structural dynamics, airframe unsteady aerodynamics, rotor aeroelasticity, drive train dynamics, servoactuator dynamics, sensor and filter dynamics, AFCSs, and pilot biomechanics. Each component is modeled in its most natural and appropriate modeling environment and then cast into state-space form. Substructures are connected using the Craig-Bampton component mode synthesis approach [19].

\section{Vehicle Models Dynamic Setup}

The aeroservoelastic models of the IAR330 and BO105 have been implemented in MASST using the technical data reported in $[20,4]$, and in chapter 4 and the related appendix A4 of [21]. These two helicopters have been selected because the required data are publicly available. The former is representative of a medium-weight articulated rotor helicopter, whereas the latter is representative of a lightweight, hingeless helicopter. The general characteristics of the two helicopters are summarized in Table 1.

The structural dynamics of the airframe are described by reducedorder models composed of six rigid-body modes (fore/aft, lateral, heave, roll, pitch, and yaw) and normal vibration modes up to $35 \mathrm{~Hz}$ for the IAR330 and up to $15 \mathrm{~Hz}$ for the BO105, based upon the available data. BO105 airframe modal data were obtained during the GARTEUR HC AG-16 [4]], and they are loosely based on data from [22]; IAR330 data were obtained during the ARISTOTEL project.

The main rotor aeroelastic models are derived using a comprehensive rotorcraft solver, CAMRAD/JA, that generates the rotor matrices for given trim conditions. A database of linearized models has been defined for several trim conditions, ranging from hover to forward flight at $120 \mathrm{kt}$ for the IAR330 and $140 \mathrm{kt}$ for the BO105, with flight speed increments of $20 \mathrm{kt}$. Collective, cyclic, and scissor modes have been included in the four-bladed articulated and hingeless main rotor models; three bending modes, two torsion modes, the axial dynamic inflow state, and the rotor speed degree of freedom have also been included, along with the six hub/pylon rigid modes required to connect the rotor to the airframe. Thus, both rotor models contain 28 degrees of freedom. The rotor blade aerodynamic loads are based on lifting-line and steady two-dimensional aerofoil characteristics, with corrections for unsteady and three-dimensional flow effects. The calculation of the loading at the blade tip is corrected for threedimensional effects using a tip loss factor. Unsteady and compressible aerodynamics effects are also considered, but only the static effects of stall are taken into account.

Different modeling approaches have been used for the tail rotor of the two helicopters, depending upon the data that were available. On the IAR330, the tail rotor has been modeled with a lateral force $Y_{T}$ applied at the tail rotor hub. The force is proportional to the lateral velocity at the center of the hub and to the tail rotor collective pitch control. The corresponding stability derivatives, $Y_{T v}$ and $Y_{T \theta_{P}}$, are scheduled with flight speed. Their values have been obtained from chapter 4 of [21]. On the BO105, the tail rotor has been modeled as a rigid teetering rotor, following the same procedure illustrated for the main rotor.

The servoactuator dynamics are modeled using transfer functions for the three main rotor swashplate actuators and for the single tail

Table 1 Helicopters: general characteristics ${ }^{a}$

\begin{tabular}{lcccc}
\hline \hline Characteristic & Symbol & IAR330 & BO105 & Units \\
\hline Gross takeoff weight & $W_{\text {TO }}$ & 7345 & 2055 & $\mathrm{~kg}$ \\
Center of mass station & $x_{\mathrm{CM}}$ & 4724 & 3318 & $\mathrm{~mm}$ \\
Maximum flight speed & $V_{\max }$ & 120 & 140 & $\mathrm{kt}$ \\
Main rotor radius & $R$ & 7.49 & 4.90 & $\mathrm{~m}$ \\
Main rotor solidity & $\sigma$ & 9.13 & 7.02 & $\%$ \\
Main rotor lock number & $\gamma$ & 8.70 & 4.31 & $\mathrm{n} . \mathrm{d}$ \\
Main rotor rotating speed & $\Omega$ & 270 & 424 & $\mathrm{rpm}$ \\
Main rotor flap frequency & $\nu_{\beta}$ & 1.03 & 1.10 & $1 / \mathrm{rev}$ \\
Main rotor lag frequency & $\nu_{\zeta}$ & 0.25 & 0.68 & $1 / \mathrm{rev}$ \\
\hline \hline
\end{tabular}

${ }^{a}$ n.d. denotes nondimensional. 
rotor actuator. The servovalve dynamics is approximated by a second-order transfer function, whereas the dynamic compliance is approximated statically.

Both models include sensors for position, velocity, and acceleration at the pilot seat in the longitudinal, lateral, and vertical directions to allow for the inclusion of the pilot's dynamics in a feedback loop. There are also three sensors to measure the angular rates $p, q$, and $r$ at the helicopter center of mass (CM).

The airframe stability derivatives, resulting from the contribution of the fuselage/wing-body, the horizontal tail, and the vertical tail, have been estimated using the aerodynamic coefficients lookup tables provided in chapter 4 of [21] to account for the vehicle model's flight dynamics behavior at the lower frequencies. It should be noted that the linearized aeroservoelastic models neglect rotor-rotor and rotor-airframe aerodynamic interference effects.

The helicopter models have been trimmed in hover and forwardflight conditions at sea level [sea level standard international standard atmosphere (ISA + 0)], achieving reasonable agreement with the results presented in chapter 4 of [21].

\section{Aeromechanical Stability Analysis}

Aeromechanical stability has been analyzed in MASST using the flutter continuation procedure [23] that follows the evolution of only the desired subset of eigensolutions for the selected parameter values (the main continuation parameter is flight speed). The models analyzed in MASST include all the degrees of freedom of the airframe and all the servoactuator dynamics. Some degrees of freedom of the main rotor (i.e., the reactionless modes, the rotor speed, and the collective lead-lag mode) have been omitted.

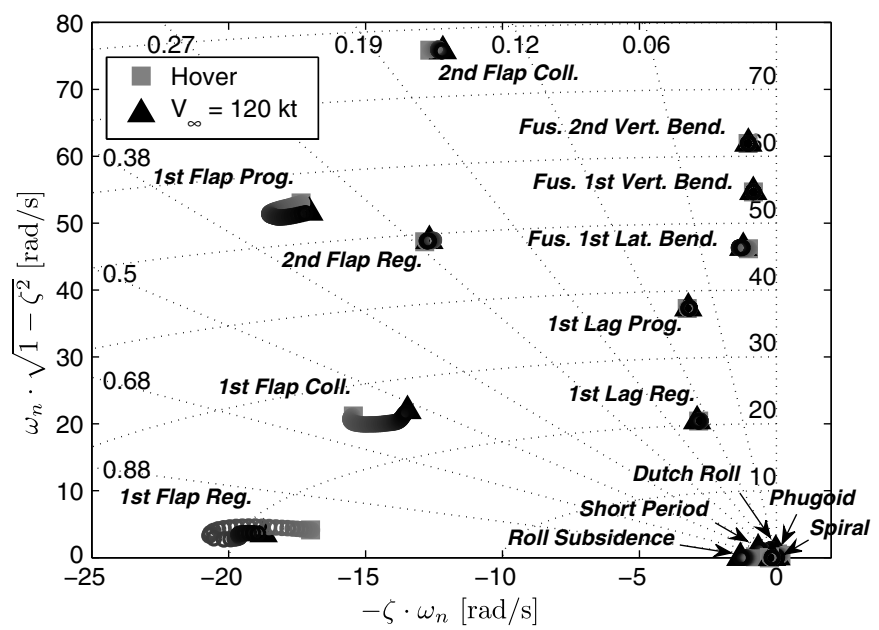

a) IAR330 - overall stability map

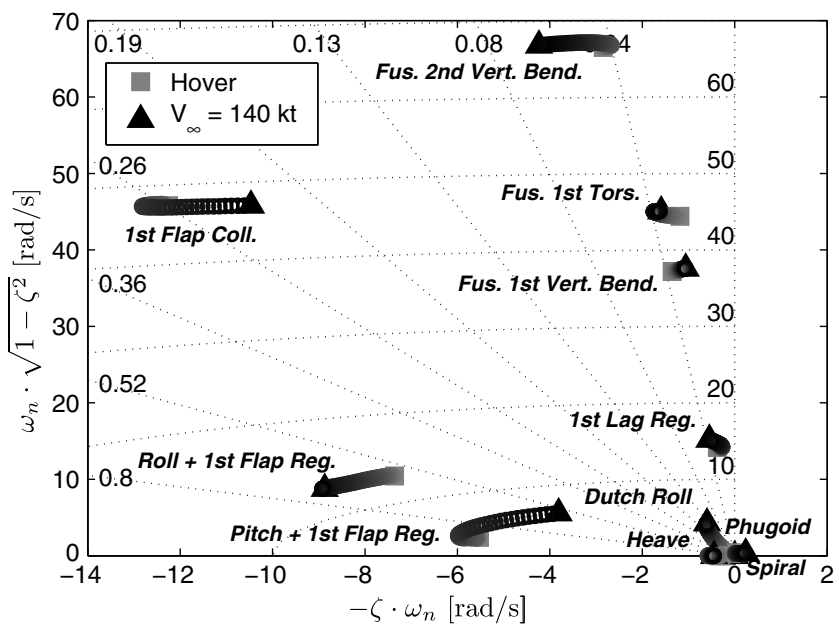

c) BO105 - overall stability map
Stability analysis results related to the IAR330 are reported in the Argand plane shown in Figs. 1a and 1b. All of the aeroelastic eigenvalues up to $80 \mathrm{rad} / \mathrm{s}$ are stable within the flight envelope. All of the main rotor roots are well damped. The airframe normal modes do not interact appreciably with the main rotor dynamics. In fact, the modal displacements of the main rotor hub are very small compared with those of the tail rotor hub and of the pilot and copilot seats. The damping of the first fuselage lateral bending mode slightly increases with flight speed. This is a consequence of the lateral force of the tail rotor, for which the stability derivative $Y_{T v}\left(V_{\infty}\right)$ increases the vehicle's overall yaw damping.

The low-frequency dynamics related to flight mechanics are generally well captured (Fig. 1b). They show similar trends with the Sud Aviation SA330 Puma eigenvalues reported in chapter 4 of [21]. The Dutch roll mode is unstable from hover up to $20 \mathrm{kt}$. The location of the Dutch roll root at a low flight speed plays an important role on the lateral handling qualities of the vehicle. The phugoid mode is always unstable, but the pilot is usually expected to be able to control this motion, as it is characterized by large time to double amplitude, at the cost of a small increase in workload. The short-period mode, roll subsidence, and spiral modes are also present.

The root locus of the BO105 is shown in Fig. 1c up to $70 \mathrm{rad} / \mathrm{s}$. Again, all of the aeroelastic eigenvalues are stable within the flight envelope. The main rotor roots are well damped except for the first lead-lag regressive pole that is located quite close to the imaginary axis. In this rotor, the lead-lag damping, mostly produced by the aerodynamic forces, is sufficient to stabilize the aircraft in all of the flight conditions investigated, even though the model shows some proneness to air resonance. The poles of the airframe are stable. The

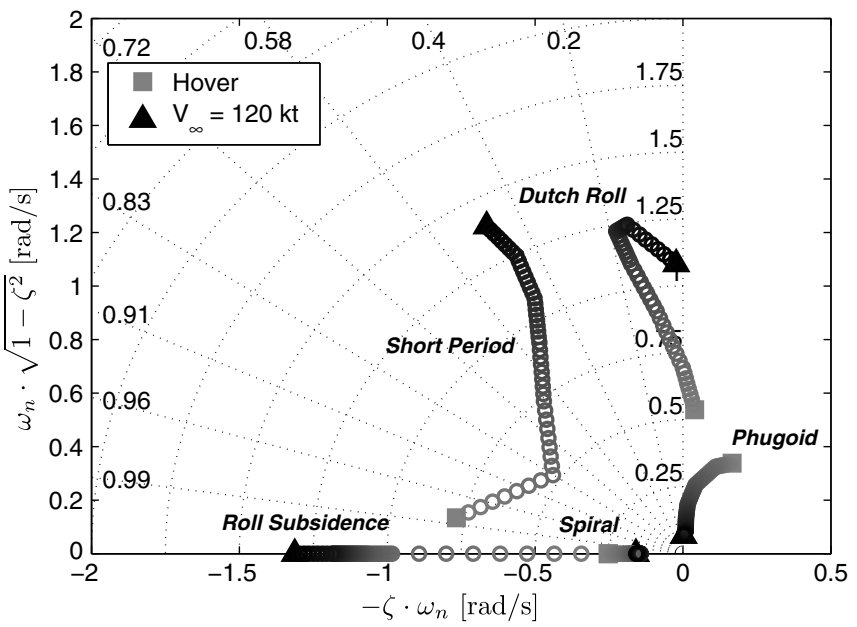

b) IAR330 - detail of flight mechanics roots

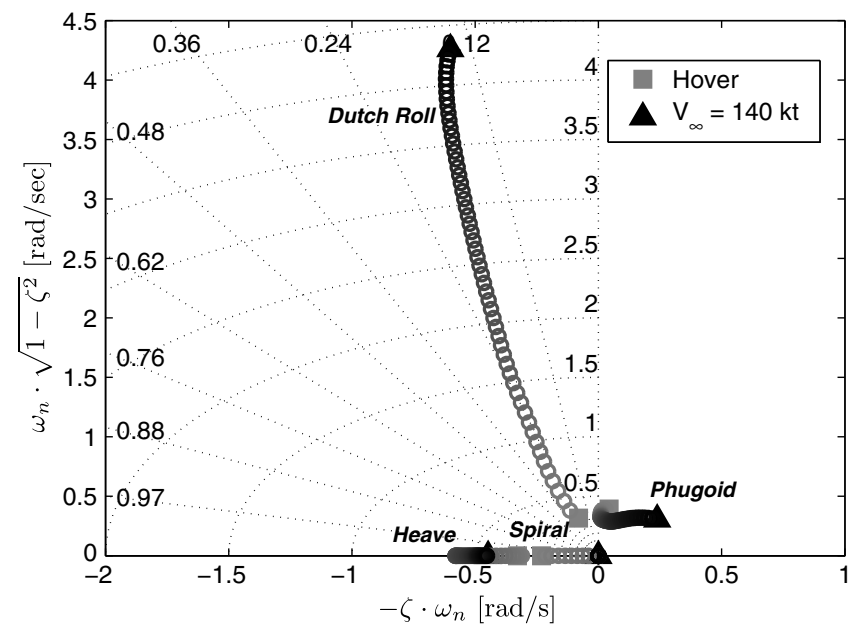

d) BO105- detail of flight mechanics roots

Fig. 1 Eigenvalues with respect to flight speed: fuselage (Fus.), vertical (Vert.), bending (Bend.), collective (Coll.), progressive (Prog.), regressive (Reg.). 
damping of the airframe poles increases with flight speed, except for the first vertical bending mode, which exhibits significant coupling with the main rotor first collective flap mode.

A more detailed view of the low-frequency eigenvalues associated with the flight mechanics-relevant modes is shown in Fig. 1d. Dutch roll, phugoid, heave subsidence, and spiral modes show the trends reported in chapter 4 of [21]. Long-period pitching oscillations, related to the phugoid dynamics, are unstable. Pitch and roll subsidence roots are coupled with the first regressive flap mode of the main rotor, generating complex-conjugate eigenvalues. These effects are related to the gyroscopic properties of the main rotor, coupled with pitch and roll airframe dynamics (chapter 4 of [21]). The eigenvalues of the rigid-body flight mechanics model obtained by statically residualizing the remaining degrees of freedom show a relatively good correlation with those presented in chapter 4 of [21] over the entire flight speed range.

Figure 2 compares the results of a lateral cyclic doublet obtained using the MASST aeroelastic model with flight-test data presented in [24]. The fundamental behavior of the vehicle appears to be captured with sufficient fidelity for the purposes of this investigation. Representativeness is sought to make it possible to transfer the outcome of the work to real vehicles. However, it is not essential at this stage, since the same models and pilots/measured transfer functions are used for both the predictive and experimental phases of the work.

Similar comparisons are not available for the IAR330 model; nonetheless, it is expected to be representative of the actual helicopter, since it was prepared in a similar manner to the BO105 using the same tools and techniques.

\section{SCAS Design}

A rudimentary stability and control augmentation system (SCAS) was designed for both helicopters according to helicopter Aeronautical Design Standard 33 (ADS-33) [25]. The ADS-33 defines the boundaries, in terms of frequency and damping ratio, related to flight mechanics roots for three handling qualities levels for rotary-wing aircraft.

The bare airframe models of both aircraft are characterized by poor handling qualities predictions, especially related to the Dutch roll and phugoid dynamics (Figs. 1b and 1d). Artificial stability is necessary to improve the handling qualities and reduce the pilot workload in hover and forward flight.

The simple SCAS developed for this study provides direct feedback between the angular rates $p, q$, and $r$ at the helicopter $\mathrm{CM}$ and the servoactuator demand signals. It includes three lowpass Butterworth filters, three proportional-integral controllers, and one cyclic mixing unit. The cutoff frequency of the second-order low-pass Butterworth filters is $10 \mathrm{~Hz}$. Filters have been introduced to account for the dynamics of the sensors and to remove highfrequency signals related to noise or external disturbances. The SCAS gains have been designed to place the flight mechanics roots inside the level 1 boundaries. The cyclic mixing unit has been
Table 2 SCAS gains

\begin{tabular}{lccc}
\hline \hline SCAS gains & IAR330 & BO105 & Units \\
\hline$K_{\varphi}$ & -0.120 & +0.020 & n.d. \\
$K_{p}$ & -0.060 & +0.008 & s \\
$K_{\vartheta}$ & -0.220 & -0.100 & n.d. \\
$K_{q}$ & -0.180 & -0.050 & s \\
$K_{\psi}$ & +0.000 & +0.000 & n.d. \\
$K_{r}$ & +0.120 & +0.100 & s \\
\hline \hline
\end{tabular}

introduced to account for the swashplate phase angle effect. The SCAS gains, reported in Table 2 , are not scheduled with flight speed. The values have been selected to obtain at least adequate predicted handling qualities within the complete flight envelope from hover to the maximum flight speed.

The flight mechanics roots of the model with SCAS both off and on are shown in Fig. 3. The SCAS places almost all the eigenvalues in the left part of the Ârgand plane, although not all roots are inside the level 1 boundaries. The SCAS is not designed to stabilize the two helicopters completely but rather to improve their handling qualities. The unstable lateral modes are characterized by large times to double amplitude. As previously stated, a pilot is expected to be able to stabilize these without a significant increase in workload.

The SCAS has been designed using the simple pole placement criteria suggested by ADS-33 [25]. Small gains that are just sufficient to meet ADS-33 level 1 boundaries have been defined to avoid excessive modification of the original helicopter dynamics and overstabilization of both vehicles, generating potentially sluggish responses. To avoid spillover problems $[26,18]$, high SCAS gains on the BO105 have not been used to prevent air resonance phenomena generated by gyroscopic mode frequencies with the main rotor leadlag regressive root, as reported in [27]

\section{B. Biodynamic Feedthrough Identification of Sway/Lateral Cyclic Stick}

Pilot biomechanical models are widely used to predict aeroservoelastic RPC phenomena. Experiments are designed to assess the pilot biodynamic feedthrough in the control inputs due to helicopter vibrations and to measure human arm impedance. Several pilot models have been proposed in the literature using data from cockpit mockup excitation (see, for example, work by Allen et al. [28], Jex and Magdaleno [5], and Höhne [29]), flight-simulator tests (see, for example, work by Mayo [30] and Masarati et al. [16]), and in-flight measurements (see, for example, work by Parham et al. [8]).

The study reported in this paper mainly focuses on aeroservoelastic RPC instabilities involving roll-lateral dynamics, and thus requires the analysis of the relationship between the pilot's lateral cyclic stick control input and the subsequent vehicle motion in the lateral direction. The involuntary biodynamics models of three test pilots have been identified in order to be able to predict the
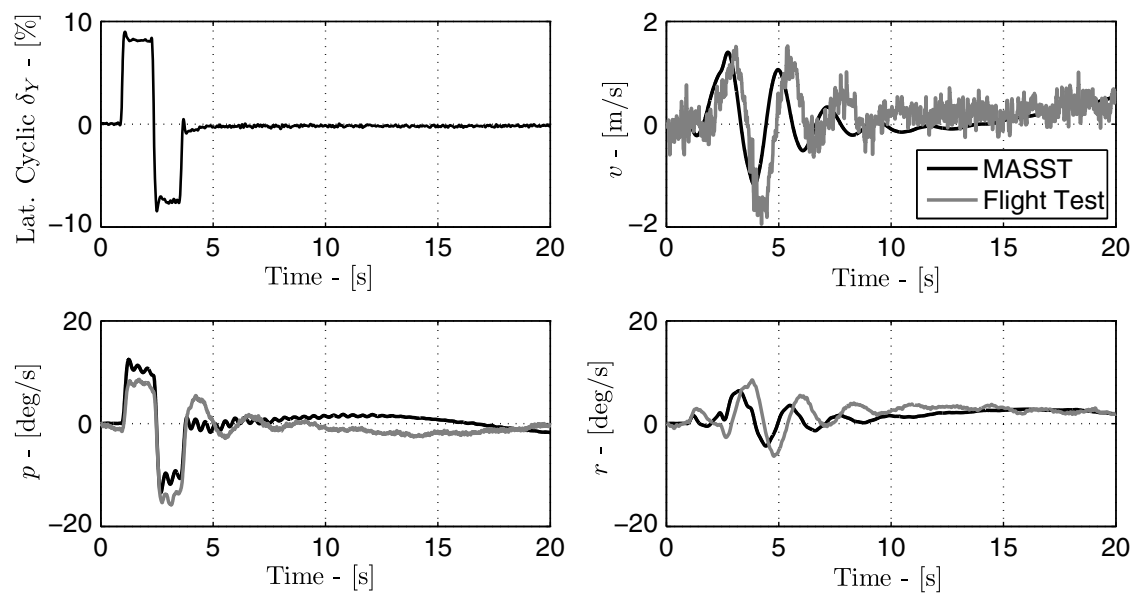

Fig. 2 BO105 response to lateral (Lat.) cyclic doublet: present vs flight-test data from [24]. 


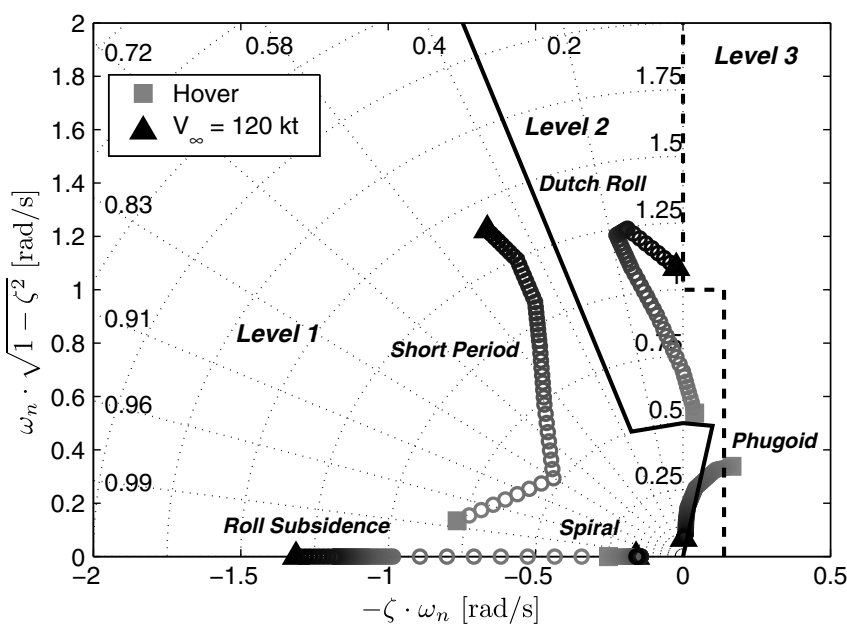

a) IAR330 - SCAS OFF

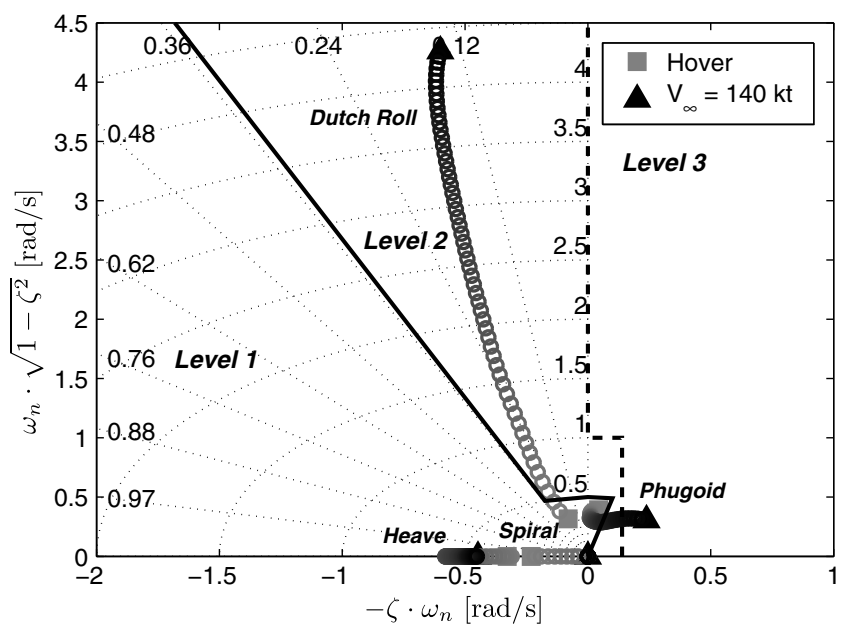

c) $\mathrm{BO105}$ - SCAS OFF

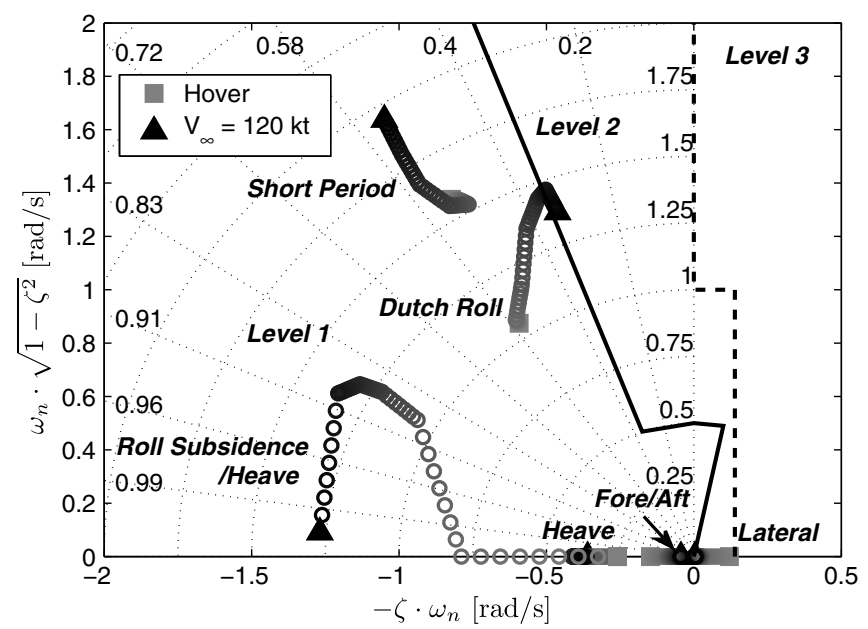

b) IAR330 - SCAS ON

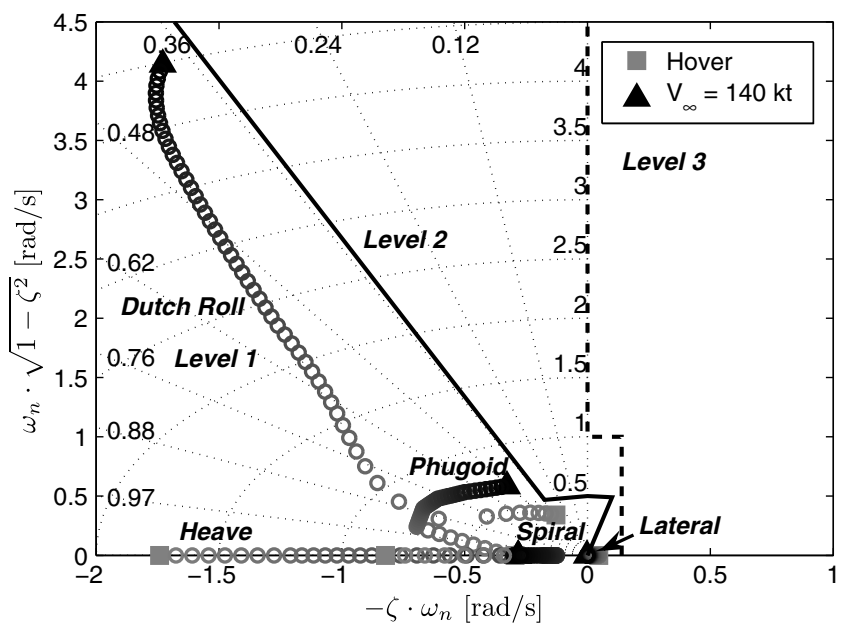

d) BO105 - SCAS ON

Fig. 3 Flight mechanics roots: SCAS off/on.

bioaeroservoelastic stability of the PVS with models that are as representative as possible of the actual PVS used in the piloted flightsimulation tests. The experiments have been conducted at the University of Liverpool (UOL) using HELIFLIGHT I in the "Bibby" flight-simulation facility.

\section{Experimental Setup}

The HELIFLIGHT I simulator is a full-motion flight simulator used for flight dynamics simulation of both fixed- and rotary-wing aircraft [31]. It is equipped with a six-degree-of-freedom motion platform, which sits atop six linear actuators, each with a bandwidth of $25 \mathrm{~Hz}$. It has a visual system with five screens, intended to reproduce pilot visual cues: three out-the-window (left, center, and right) screens and two "chin" windows to allow the extended vertical view associated with rotary-wing aircraft. It is normally used to simulate the dynamics of an air vehicle while providing suitable motion, haptic, visual, and audio cueing to the pilot. The vehicle models used for this study in the simulation facility were developed using the Advanced Rotorcraft Technologies FLIGHTLAB software [32].

During the biodynamic characterization of the pilots that would subsequently perform the flight-simulator assessment tests, the same flight simulator was used as a shaker to excite the pilot's biodynamic response. The motion induced in the control inceptors by the oscillations imposed on the cockpit were measured, along with the corresponding limb motion. The flight simulator was therefore used in a somewhat unconventional manner as a vibration platform to excite the biodynamics of the pilot along the lateral axis without any specific visual cueing. During the test, the human subject was seated inside the simulator holding the control inceptors. The pilot was instructed to avoid trying to compensate for any high-frequency stick motions. The pilot's only task was to try to maintain the stick in its nominal initial position. The experimental setup described in [16] was used; the interested reader is referred to that document for further details.

\section{Transfer Function Identification}

Three trained test pilots were considered in the biodynamic feedthrough characterization campaign. During the tests, the centered inceptor position $(0 \%)$ was used as reference. The control inceptor retention force was always active. The stick forces were set to those used as "nominal" for rotorcraft flight trials in that facility.

To identify the pilot/device BDFT transfer function, the lateral acceleration measured on the flight-simulator pod, $a_{Y}^{\text {seat }}(t)$, was used as input. The lateral stick position recorded by the flight simulator, $\delta_{Y}(t)$, was used as output.

The flight-simulator input was supplied in the form of a set of desired, specific, force time histories. The excitation consisted of colored noise signals, with a frequency range up to $10 \mathrm{~Hz}$, zero mean, and a root mean square of $0.004 \mathrm{~g}(99.96 \%$ amplitude within $0.01 \mathrm{~g})$. The flight simulator was excited only in the lateral direction.

Three different transfer functions were identified: one for each test pilot involved in the test campaign. A preliminary analysis of these datasets was performed to assess the information contained in the different tests. Subsequently, the transfer functions were identified using simple single-input/single-output (SISO) identification techniques in the frequency domain, using the MATLAB System Identification toolbox. 
All measured data were bandpass filtered using an optimal Butterworth filter with a passband between 0.5 and $10 \mathrm{~Hz}$ to isolate the frequencies of interest. After filtering, the coherence between the input and output signals was evaluated. When the coherence level was considered satisfactory, the Blackman-Tukey algorithm ([33] chapter 6) was used to estimate the frequency response function (FRF). Finally, the FRF was fitted using a rational output-error polynomial model.

Generally, a good level of coherence $(\geq 0.8)$ was obtained between the lateral acceleration of the flight-simulator pod and the lateral stick rotation measured by the flight-simulator encoders in the frequency band up to $10 \mathrm{~Hz}$. The pilot/lateral stick dynamics are identified using rational polynomial transfer functions (TFs) with a third-order denominator and a first-order numerator. The structural model equivalent to the pilot/lateral stick dynamics in the Laplace domain is

$$
\frac{\delta_{Y}}{a_{Y}^{\text {seat }}}=H_{P P}(s)=-\mu_{P} \frac{s T_{z}+1}{s T_{p}+1} \frac{1}{\left(s / \omega_{n}\right)^{2}+2 \xi\left(s / \omega_{n}\right)+1}
$$

The two complex-conjugate poles represent the dynamics associated with the pilot biomechanics and the control device. The low-frequency real pole represents the integral contribution of the pilot's voluntary action. The (usually high frequency) zero restores the correct asymptotic behavior of the transfer function.

The properties identified for the three test pilots are reported in Table 3 . The complex-conjugate biodynamic poles are well damped, with $\bar{\xi}>20 \%$. Test pilot 3 has the highest damping ratio: close to $40 \%$. The natural frequencies $\omega_{n}$ range between 2 and $3 \mathrm{~Hz}$. Pilot 1 shows the lowest frequency of $2.16 \mathrm{~Hz}$, whereas that of pilot 2 is $2.95 \mathrm{~Hz}$. The frequency of pilot 3 of $2.36 \mathrm{~Hz}$ is close to that of pilot 1 , but the damping factor $\xi$ is much higher and the gain $\mu_{P}$ is much lower. The Bode plots of the individual pilot's transfer functions are shown in Fig. 4.

The static gain $\mu_{P}$ of the transfer function of pilot 1 is higher than that of the other pilots. Moreover, the low natural frequency of the biodynamic pole of pilot 1 causes a phase reduction at frequencies lower than the other pilots' transfer functions. The different results obtained for test pilot 1, compared with the other test pilots, are probably related to his anthropometric characteristics: pilot 1 belongs to the 99th percentile in terms of height and weight, showing somewhat different biomechanical properties from those of an average individual.

Finally, it is worth noting that all of the transfer functions also present a (pseudo)integral action $(\approx 1 / s)$ in the low-frequency range below $1 \mathrm{~Hz}$, characterized by the low-frequency pole $-1 / T_{p}$ (between 0.3 and $0.6 \mathrm{~Hz}$ ). This contribution can be attributed to the voluntary action the pilot exerts while trying to keep the control inceptor about the nominal position, thus acting as a regulator. The integral action also affects the involuntary (i.e., passive) pilot dynamics, increasing the phase delay $(\angle(1 /(j \omega))=-90 \mathrm{deg})$, and thus reducing the phase margin of the closed-loop PVS with respect to lateral PAO proneness, as reported in the next section.

The model of Eq. (1) is consistent with models proposed in the open literature; the transfer functions of Fig. $\underline{4}$ are similar to those presented in figure 6 of [8], which were measured in flight. The notion of modeling the involuntary dynamics of the pilot at frequencies beyond the typical pilot's bandwidth as a second-order lowpass filter in series with a crossover-like model of the voluntary action is also present; for example, in Hess's "structural pilot" model [34] and in the work of Szabolcsi [35].

Table 3 Pilot/lateral stick dynamic properties

\begin{tabular}{lrrrc}
\hline \hline & Pilot 1 & Pilot 2 & Pilot 3 & Units \\
\hline$\mu_{P}$ & 216.26 & 88.67 & 83.88 & $\% / \mathrm{g}$ \\
$T_{z}$ & 0.02 & 0.05 & 0.03 & $\mathrm{~S}$ \\
$T_{p}$ & 0.51 & 0.49 & 0.26 & $\mathrm{~s}$ \\
$\xi$ & 26.87 & 23.11 & 39.66 & $\%$ \\
$\omega_{n}$ & 13.59 & 18.53 & 14.81 & $\mathrm{rad} / \mathrm{s}^{-1}$ \\
\hline \hline
\end{tabular}
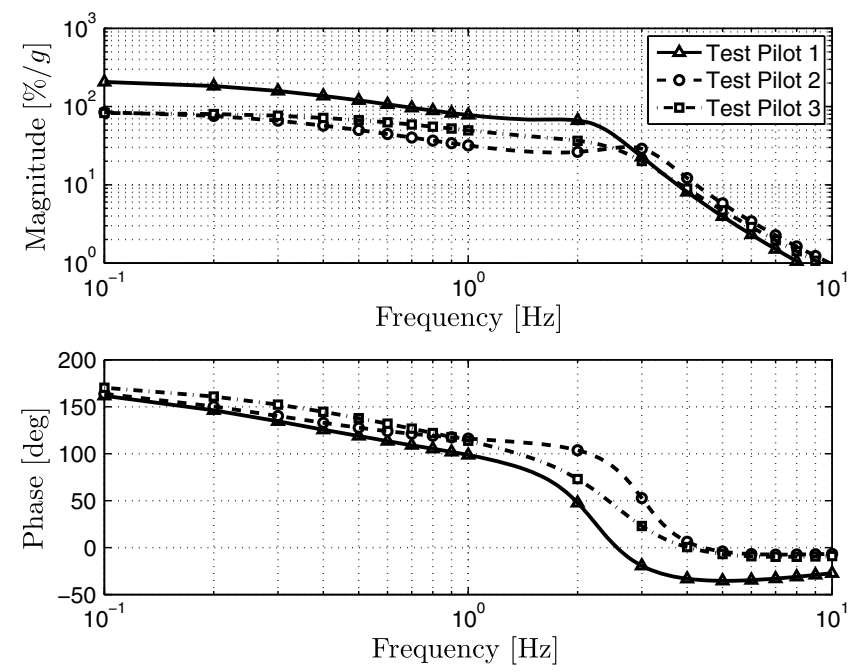

Fig. 4 Identified pilot/lateral stick BDFT properties.

\section{Pilot-in-the Loop Stability Analysis}

PAO phenomena involving roll/sway motions have been investigated using the three experimental pilot/lateral stick TFs reported in the previous section.

Stability analyses were performed using the Nyquist criterion for SISO systems, considering the feedback loop between the lateral acceleration at the pilot seat $a_{Y}^{\text {seat }}$ and the lateral cyclic pitch $\theta_{1 c}$. The SISO transfer functions of the IAR330 and of the BO105 helicopters parameterized at several trim conditions collected in a vector $\boldsymbol{p}$,

$$
a_{Y}^{\text {seat }}=H(s, \boldsymbol{p}) \cdot \theta_{1 c}
$$

have been computed using MASST. The helicopters' TFs (including the SCAS dynamics) present an unstable pole related to the lateral flight mechanics mode (labeled "Lateral" in Figs. $3 \mathrm{~b}$ and $3 \mathrm{~d}$, at the bottom-right corner). Since these dynamics are well separated in frequency from those of interest, which are related to the involuntary pilot response, the helicopters' TFs have been decomposed into stable $H_{S}$ and unstable $H_{U}$ submodels $H(s, \boldsymbol{p})=H_{S}(s, \boldsymbol{p})+$ $H_{U}(s, \boldsymbol{p})$, and only the stable submodels $H_{S}(s, \boldsymbol{p})$ have been considered in the subsequent analyses. In fact, the very long time to double amplitude of the unstable modes is easily controlled by the pilot's voluntary action on the controls, so they do not represent a problem for this study. This procedure is in fact helpful for this study, as those modes would have produced an intrinsically unstable loop transfer function (LTF), hiding any loss of stability margin introduced by the transfer function that describes the involuntary action of the pilot.

Reasonable values of gearing ratios between the nondimensional lateral stick rotation and the main rotor lateral cyclic pitch have been estimated for the IAR330 $\left(G_{1 c}=0.105 \mathrm{deg} / \%\right)$ and for the BO105 $\left(G_{1 c}=0.05 \mathrm{deg} / \%\right)$ by parameterizing the range of possible cyclic pitch values available for both helicopters (approximately 19 deg for the IAR330 and $10 \mathrm{deg}$ for the BO105) on the HELIFLIGHT I control inceptors.

Table 4 Predictions matrix

\begin{tabular}{lccc}
\hline \hline Case no. & Flight speed $V_{\infty}, \mathrm{kt}$ & Gain $G_{Y}$ & Time delay $\tau_{Y}, \mathrm{~ms}$ \\
\hline 1 & 0.0 & 1.0 & 0.0 \\
2 & 80.0 & 1.0 & 0.0 \\
3 & 120.0 & 1.0 & 0.0 \\
4 & 0.0 & 2.5 & 0.0 \\
5 & 80.0 & 2.5 & 0.0 \\
6 & 120.0 & 2.5 & 0.0 \\
7 & 0.0 & 2.5 & 140.0 \\
8 & 80.0 & 2.5 & 140.0 \\
9 & 120.0 & 2.5 & 140.0 \\
\hline \hline
\end{tabular}


The LTF of the PVS model is

$$
\operatorname{LTF}(s, \boldsymbol{p})=-G_{Y} e^{-\tau_{Y} s} H_{S}(s, \boldsymbol{p}) G_{1 c} H_{P P}(s)
$$

where $G_{Y}$ and $\tau_{Y}$ are, respectively, the gain and the time delay on the lateral cyclic control; and $H_{P P}(s)$ is the identified pilot/lateral stick transfer function, multiplied by the gearing ratio $G_{1 c}$. The minus sign in Eq. (3) is introduced because the pilot contribution provides a negative feedback loop closure.

The $3 \times 3$ matrix of the test conditions considered to predict PAO proneness is shown in Table 4 . Three flight speeds are considered:

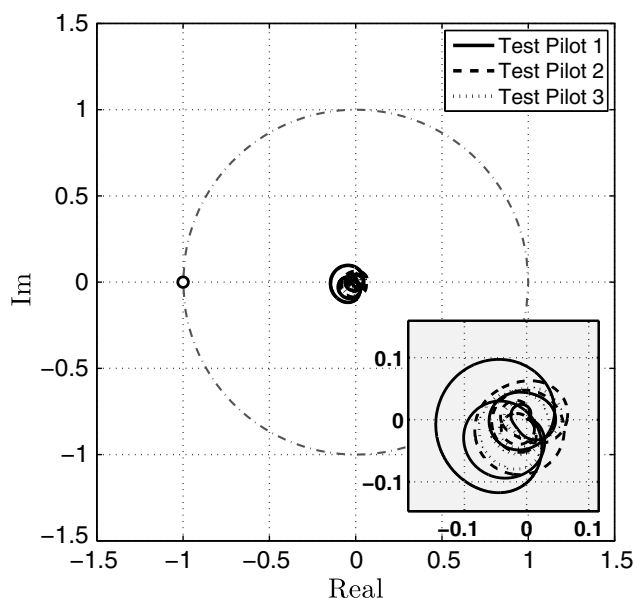

a) IAR330, $V_{\infty}=0 \mathrm{kt}$

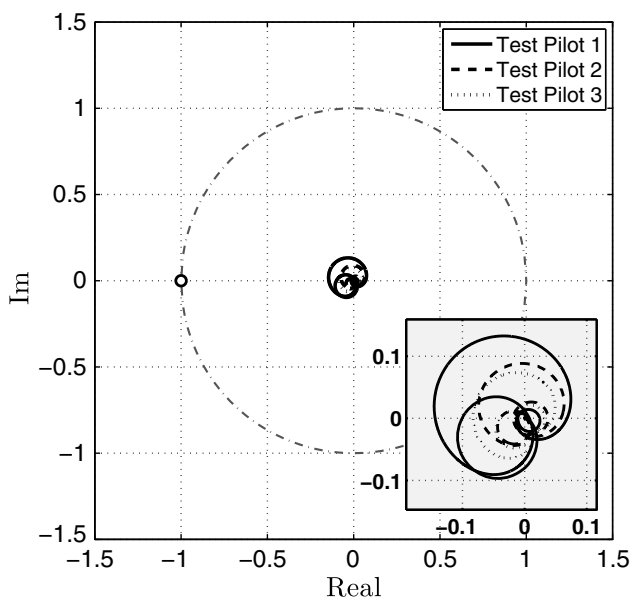

c) IAR330, $V_{\infty}=80 \mathrm{kt}$

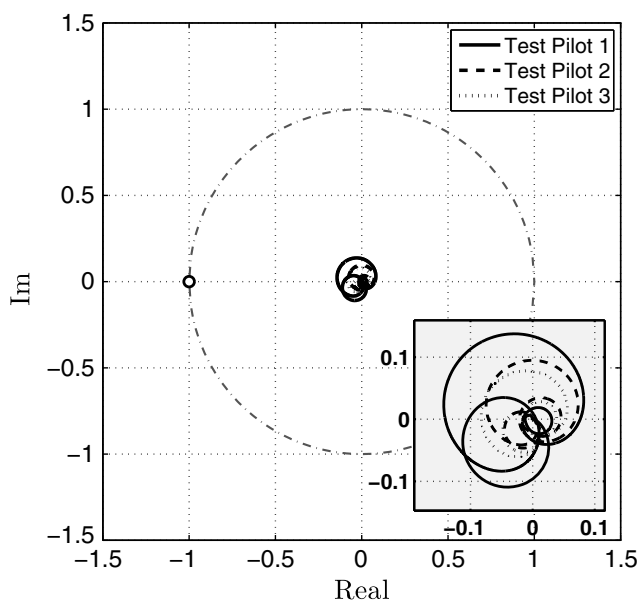

e) IAR330, $V_{\infty}=120 \mathrm{kt}$ hover, $80 \mathrm{kt}$, and $120 \mathrm{kt}$ [at sea level standard (ISA + 0)]. Three combinations of gearing ratio $G_{Y}$, between the lateral cyclic stick deflection and blade lateral cyclic pitch, and of time delay $\tau_{Y}$, between the control deflection and the actual blade pitch change, have been considered: nominal, $G_{Y}$ increased by a factor 2.5 , and $140 \mathrm{~ms} \tau_{Y}$ in addition to increased $G_{Y}$. For instability to occur, the gain must increase such that the LTF exceeds $0 \mathrm{~dB}$ and the time delay must increase to a point that phase margin is depleted. The high gain (2.5) increase ensures that a $0 \mathrm{~dB}$ crossover frequency is present. Then, the combination of high gain (2.5) and time delay (140 ms) decreases phase margin to the point of instability. The introduction of a time

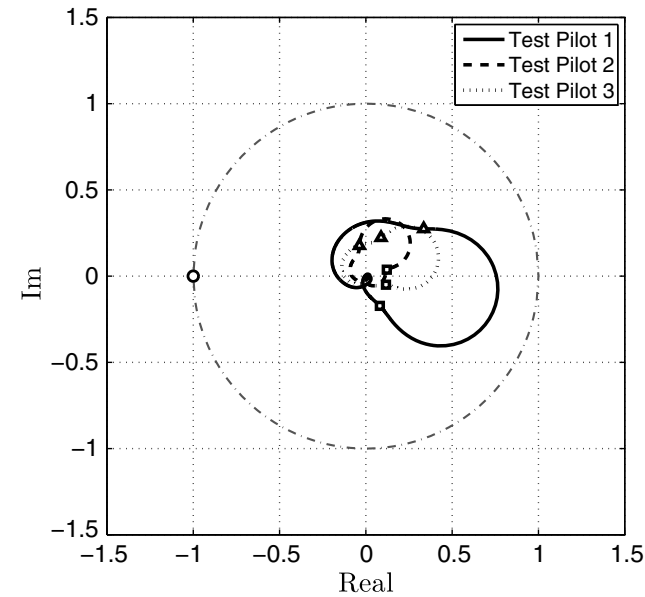

b) $\mathrm{BO105}, V_{\infty}=0 \mathrm{kt}$

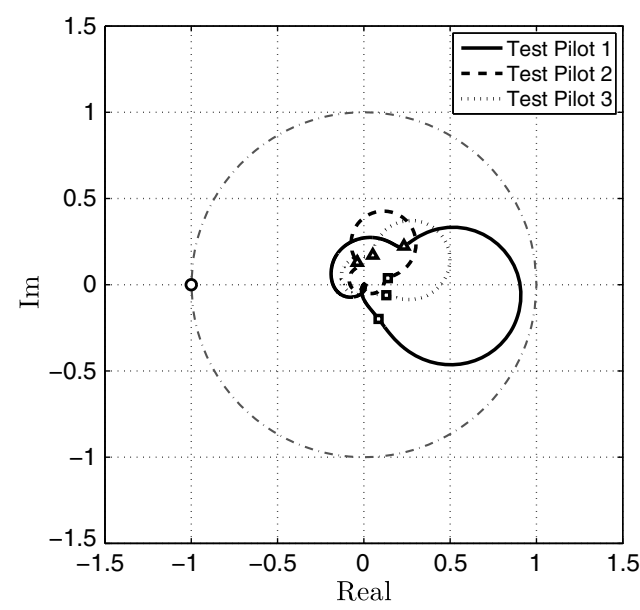

d) $\mathrm{B0105}, V_{\infty}=80 \mathrm{kt}$

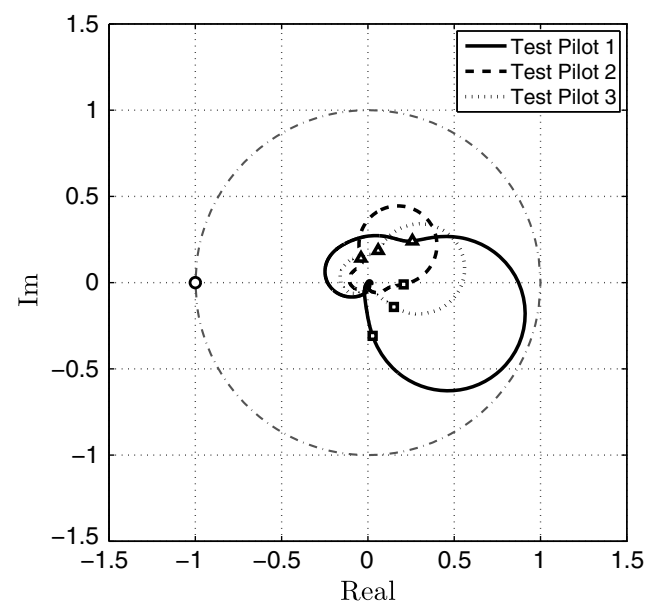

f) $\mathrm{BO105}, V_{\infty}=120 \mathrm{kt}$

Fig. 5 Nyquist plots of the LTF in nominal conditions: $G_{Y}=1.0$ and $\tau_{Y}=0.0 \mathrm{~ms}$. 
delay is often justified by its ability to increase the workload of the pilot and trigger PIO instabilities. Time delays in the control system of actual aircraft are introduced by fly-by-wire systems, specifically by the digital acquisition and filtering of control device motion and by signal processing before feeding inputs to the actuators. Delays of the order of $80 \mathrm{~ms}$ are plausible, but higher values have been reported, especially in early experimental aircraft (see, for example, the discussion in [9]).

The results reported in this section will be used to discuss the proneness of the PVS to roll/lateral PAO instabilities. In particular, the behavior of the IAR330 and the BO105 with rather different flight conditions and design parameters is discussed.

Figure 5 compares the results obtained for nominal conditions (configurations 1,2, and 3), considering the biodynamics of the three test pilots in a feedback loop with the aeroservoelastic models of the IAR330 and the BO105 for the hover and forward-flight conditions. The configurations with nominal gain and no time delay have Nyquist plot results that remain inside the circle of unit radius, and the corresponding closed-loop systems are always characterized by robust stability margins. On the BO105, the lightly damped lead-lag

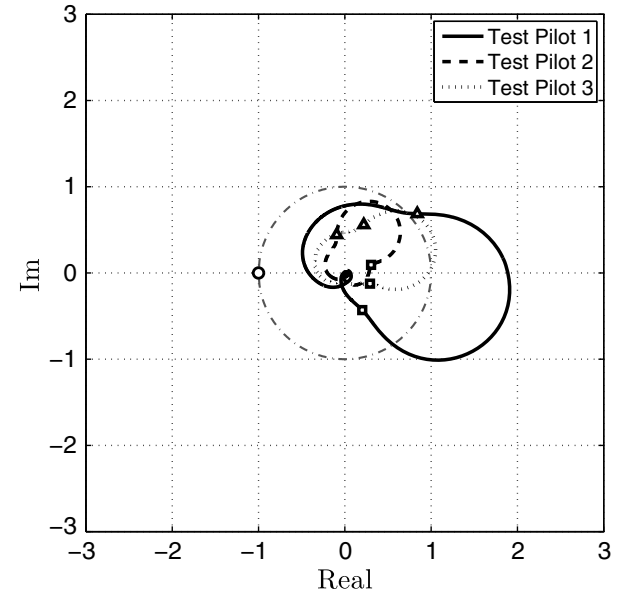

a) $V_{\infty}=0 \mathrm{kt}-G_{Y}=2.5, \tau_{Y}=0.0 \mathrm{~ms}$

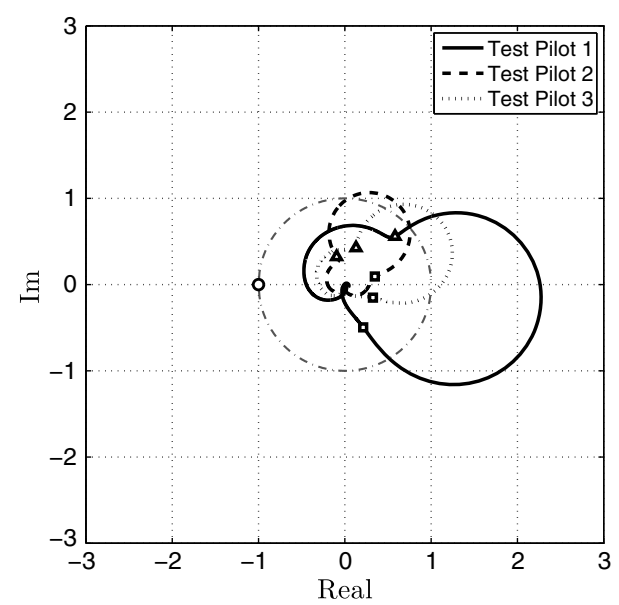

c) $V_{\infty}=80 \mathrm{kt}-G_{Y}=2.5, \tau_{Y}=0.0 \mathrm{~ms}$

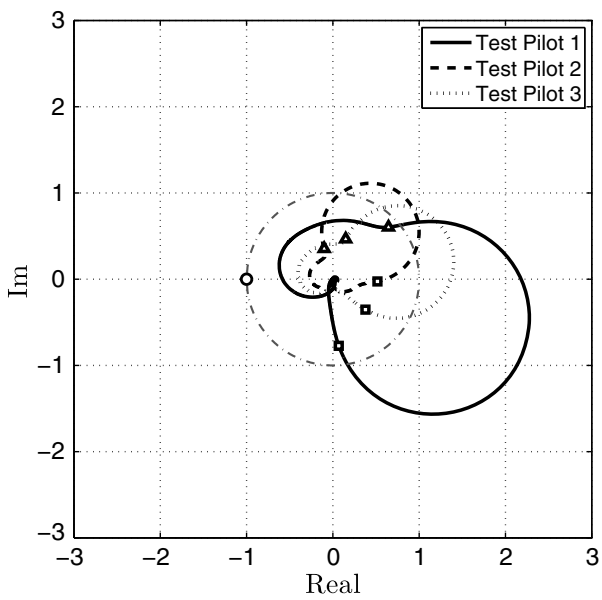

e) $V_{\infty}=120 \mathrm{kt}-G_{Y}=2.5, \tau_{Y}=0.0 \mathrm{~ms}$

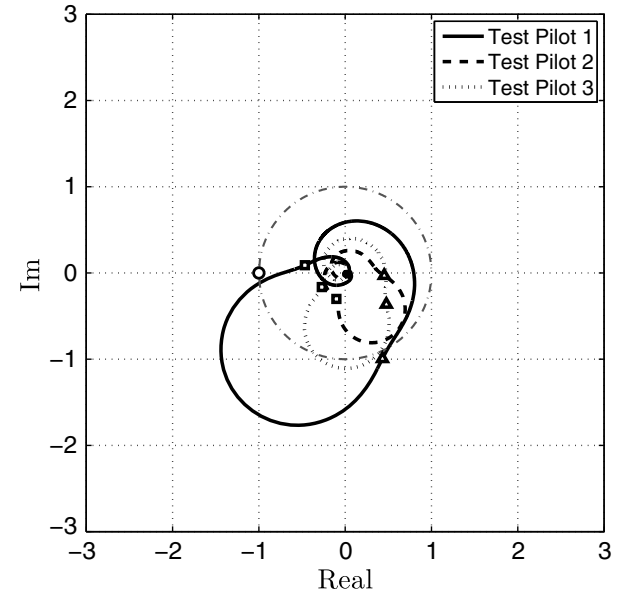

b) $V_{\infty}=0 \mathrm{kt}-G_{Y}=2.5, \tau_{Y}=140.0 \mathrm{~ms}$

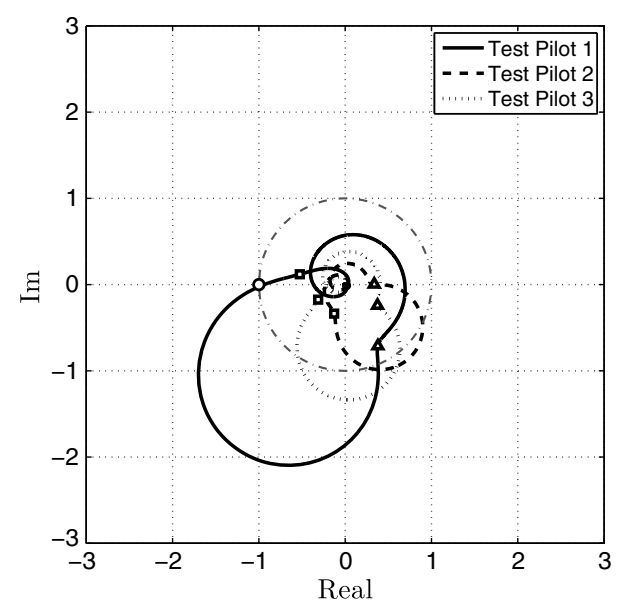

d) $V_{\infty}=80 \mathrm{kt}-G_{Y}=2.5, \tau_{Y}=140.0 \mathrm{~ms}$

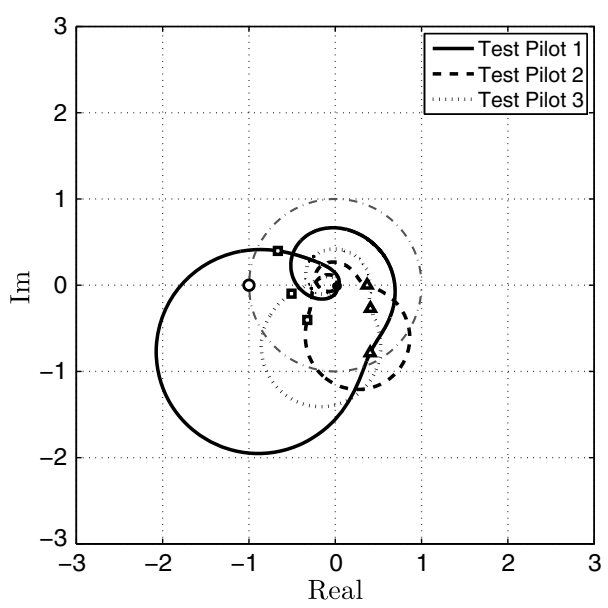

f) $V_{\infty}=120 \mathrm{kt}-G_{Y}=2.5, \tau_{Y}=140.0 \mathrm{~ms}$

Fig. 6 Nyquist plots of the LTF: $G_{Y}=2.5 ; \tau_{Y}=0 \mathrm{~ms}$ (left) and $\tau_{Y}=140.0 \mathrm{~ms}$ (right). 
regressive mode of the main rotor results in an enlargement of the LTF's lobe between $2.1 \mathrm{~Hz}$ (indicated with $\Delta$ ) and $2.5 \mathrm{~Hz}$ (indicated with $\square$ ). The differences between the three pilots are clearly visible. Test pilot 1 is characterized by a larger lobe caused by a static gain of the pilot's biodynamic TF $\left(\mu_{P}=216.26 \% / \mathrm{g}\right.$; Table 3$)$ higher that that of the other pilots. Moreover, the LTF of test pilot 1 is also the one that is the most shifted toward point $(-1+j 0)$ in the Argand plane (see Fig. 5) compared with that of the other two test pilots. Finally, the LTF's static gain increases with the flight speed, whereas the phase of the LTF reduces. As a consequence, the BO105 model is predicted to be more prone than the IAR330 model to roll/lateral PAO instabilities. At the same time, test pilot 1 shows a higher tendency to PAO than the other test pilots when interacting with the aeroelastic model of the BO105.

Configurations 4,5 , and 6 , characterized by a larger lateral gearing ratio $G_{Y}(2.5$ times the nominal value $)$ and no time delay, are shown in Fig. 6 (left column). The increase in gain alone is not sufficient to make the locus of any of the LTF curves circumvent the point $(-1+j 0)$. Again, the stability margin of the BO105 reduces when the flight speed increases.

Configurations 7, 8, and 9, shown in Fig. 6 (right column), in addition to the same $G_{Y}=2.5$ of the previous cases, contain a $140 \mathrm{~ms}$ time delay. The time delay produces a clockwise rotation of the Nyquist curves, with a significant reduction of the phase margin on the BO105, driving test pilot 1 to the boundary of stability at $80 \mathrm{kt}$ (Fig. 6d) and toward a strong PAO instability at $120 \mathrm{kt}$ (Fig. 6f). Test pilots $\overline{2}$ and 3 are not predicted to jeopardize the stability of the coupled system as severely as pilot 1 .

The results of Figs. $6 \mathrm{~d}$ and $6 \mathrm{f}$ indicate that the LTFs for pilots 2 and 3 also result in a reduced phase margin, which would make the system unstable with an additional 50 to $100 \mathrm{~ms}$ of time delay. However, during the piloted simulation phase of the investigation, such an increase in time delay, alongside the high gearing ratio, was judged as being unrealistic by the pilots, as it would result in an intolerable workload and lead to very poor vehicle handling qualities. In fact, time delays higher than $140 \mathrm{~ms}$ could not be used according to the pilots' judgment.

These predictions suggest that the roll/lateral PAO phenomena are 1) more likely to occur on helicopters with soft in-plane rotors that have lightly damped in-plane rotor modes; 2) more sensitive to time delay than gearing ratio with respect to the lateral cyclic control; 3) more dangerous when the flight speed increases (higher accelerations perceived by the pilot due to higher control moments generated by the main rotor); and 4) more likely to occur with pilots that are characterized by a natural frequency of the biodynamic poles that is close to the lightly damped in-plane rotor mode.

To demonstrate the aeroelastic nature of the roll/lateral PAO predictions, the LTF resulting from the rigid-body (RB) model of the BO105 (obtained by statically condensing the aeroservoelastic modes to give the six RB degrees of freedom model) was compared with the corresponding aeroelastic LTF. The Nyquist plots are shown in Fig. 7. Although the same lateral cyclic gain and time delay of case 9 have been used in both cases, the results for the RB case do not violate Nyquist's stability criterion. The RB model does not contain the elastic degrees of freedom required to destabilize the closed-loop PVS model. Specifically, the lead-lag regressive mode of the main rotor is absent. In this case, all test pilot models yield a stable PVS prediction, according to the Nyquist plots.

\section{Impact of Regressive Lead-Lag Mode Damping on PAO Proneness}

The PAO predicted for the BO105 is related to the loss of stability margin of the lateral acceleration/cyclic pitch control LTF caused by the spillover of the lightly damped regressive lead-lag mode. This is confirmed by the fact that increasing the damping of the lead-lag regressive mode reduces the magnitude of the lobe in the Nyquist plots.

Figure $\underline{8}$ shows the effect of increasing the viscous lead-lag damping coefficient on the Nyquist plots at $120 \mathrm{kt}$. The viscous coefficient has been selected to increase the damping ratio of the lead-lag regressive mode to two and four times the nominal value. All cases have been evaluated in the worst condition, i.e., $G_{Y}=2.5$ and $\tau_{Y}=140 \mathrm{~ms}$. The results show that a damping ratio equal to four times the nominal value, i.e., $\zeta=10 \%$ (which is obtained with a viscous coefficient of $\left.C_{\zeta}=5350 \mathrm{~N} \cdot \mathrm{m} \cdot \mathrm{s} \cdot \mathrm{rad}^{-1}\right)$ is required to reach a stable PVS with test pilot 1 .

The IAR330 does not show any proneness to roll/lateral PAO instability. The pilots' biodynamics do not couple with the aeroservoelastic frequencies of the helicopter. In detail, the lead-lag regressive mode of the IAR 330 at $80 \mathrm{kt}$ is placed at $3.23 \mathrm{~Hz}$, which is a frequency above that of the pilots' biodynamics poles. Moreover, the viscous coefficient of the IAR330's main rotor lead-lag dampers is $C_{\zeta}=7000 \mathrm{~N} \cdot \mathrm{m} \cdot \mathrm{s} \cdot \mathrm{rad}^{-1}$, which yields a $15 \%$ damping ratio of the lead-lag regressive mode at $80 \mathrm{kt}$.

\section{Flight-Simulator Experimental Results}

To verify the roll/lateral PAO instabilities predicted in the previous section, the linearized aeroservoelastic models of the IAR330 and BO105, augmented with their respective SCASs, were implemented in state-space form in the FLIGHTLAB software environment of the HELIFLIGHT I flight simulator [31]. The aeroservoelastic models were flown by the same test pilots used for the identification of the pilot/lateral stick biodynamics properties.

The usual flight-simulation engine integrates the dynamics of nonlinear vehicle models developed using the Advanced Rotorcraft Technologies FLIGHTLAB software [32]. For this investigation, however, linear helicopter models in state-space form generated using MASST were loaded into a dummy FLIGHTLAB model to drive the simulator. The real-time simulation output of these models

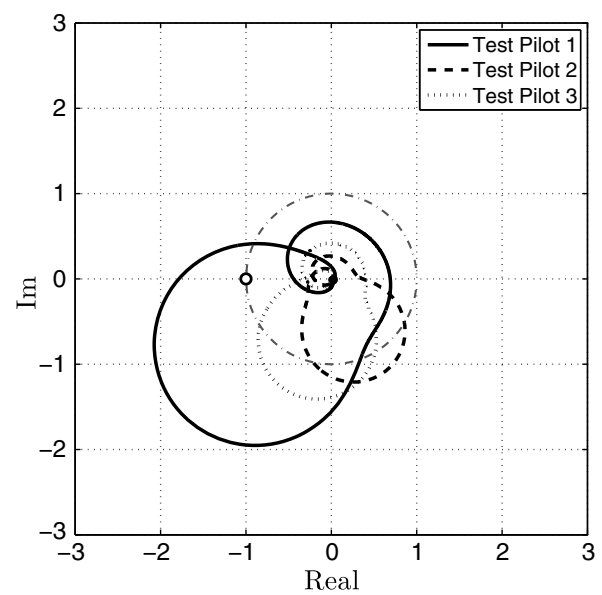

a) Aeroservoelastic

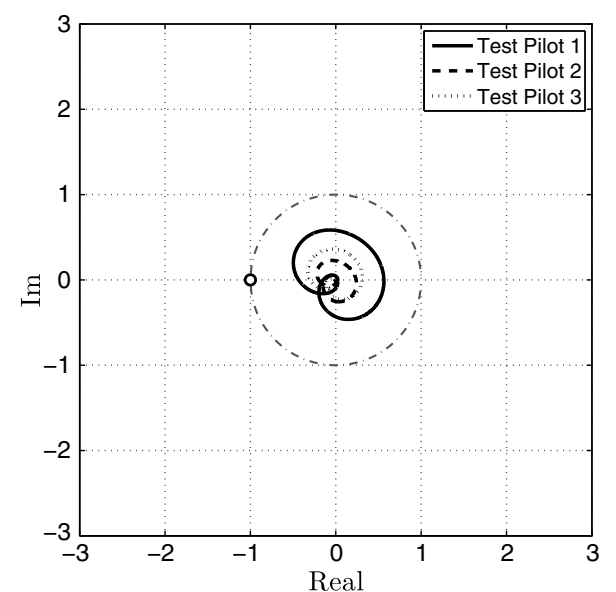

b) Rigid body

Fig. 7 Nyquist plots of the LTF for a) ASE and b) RB BO105 at $120 \mathrm{kt}$ : $G_{Y}=2.5$ and $\tau_{Y}=140.0 \mathrm{~ms}$. 


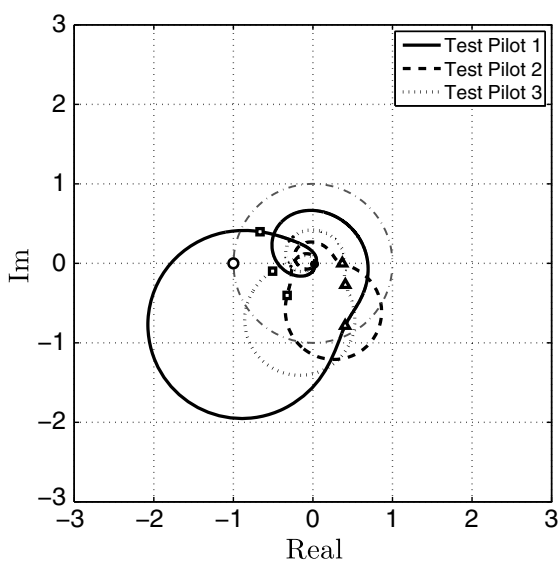

a) $\zeta=2.5 \%$ (nominal)

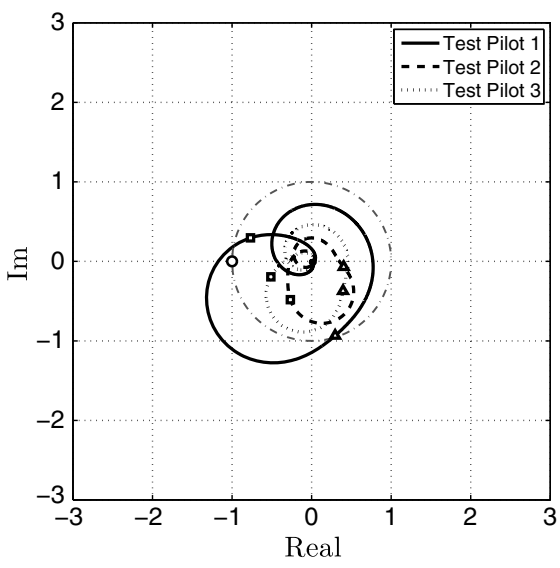

b) $\zeta=5.0 \%(2 \times$ nominal $)$

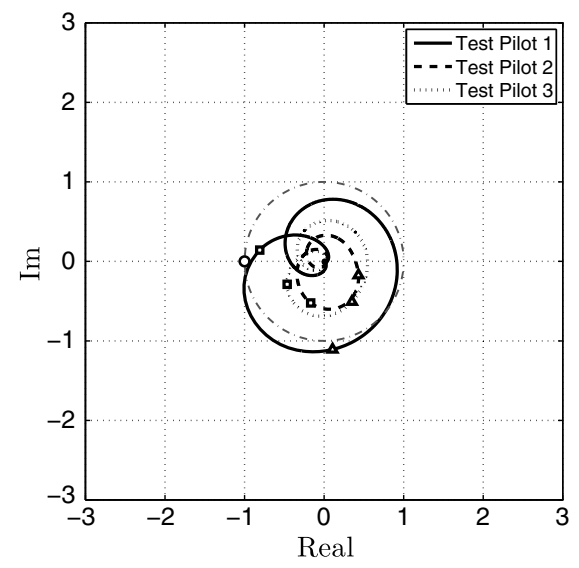

c) $\zeta=10.0 \%(4 \times$ nominal $)$

Fig. 8 Nyquist plots of the LTF with different lead-lag damping: $G_{Y}=2.5$ and $\tau_{Y}=140.0 \mathrm{~ms}$.
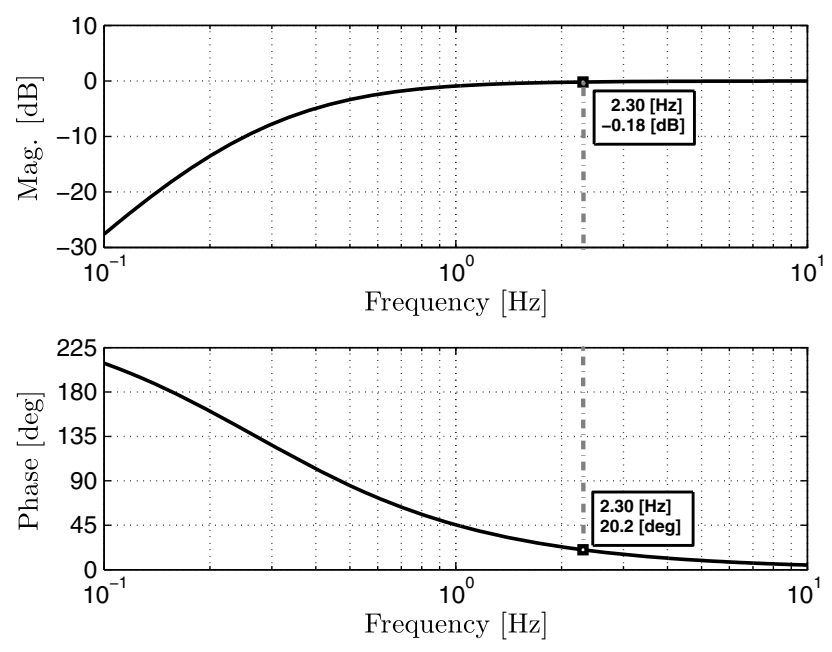

Fig. 9 Bode plot of washout filter transfer function.

was used to drive the motion platform and the external world visualization. Similarly, real-time simulation inputs were connected to the flight-simulator control inceptors.

The flight-simulator data acquisition was managed via the FLIGHTLAB real-time interface. A sampling period of $10 \mathrm{~ms}$ was used for all of the acquisition channels. Bespoke software was developed to capture and save all of the data that were being broadcast across the simulation facility's Ethernet.
The flight-simulator motion system is characterized by a sequence of filters between the demanded accelerations and the actual motion of the legs. The purpose of the filters is to limit the demanded motion to comply with travel constraints, structural load limitations, and safety requirements for the pod's occupants.

In addition to the motion base's washout dynamics, the flight simulator includes some intrinsic time delays related to the control inceptors. These combined effects have an impact on the effective time delay necessary to destabilize the PVS. The previously illustrated predictions indicate that a time delay of $140 \mathrm{~ms}$ is required to reach the stability limit of the PVS at $80 \mathrm{kt}$.

The loop transfer function of the PVS, including the flightsimulator dynamics, is

$$
\operatorname{LTF}_{\text {sim }}(s, \boldsymbol{p})=-G_{Y} e^{-\left(\tau_{Y}+\tau_{\text {sim }}\right) s} H_{S}(s, \boldsymbol{p}) G_{1 c} H_{P P}(s) H_{\mathrm{WO}}(s)
$$

where the time delay $\tau_{\text {sim }}$ related to the flight-simulator control stick inceptor data acquisition $(70 \mathrm{~ms})$ and the washout filter TF $H_{\mathrm{WO}}(s)$ for the sway motion are considered. The Bode plot of function $H_{\text {WO }}(s)$, essentially a third-order high-pass filter with three poles at about $1.7 \mathrm{rad} / \mathrm{s}$ and three zeros (two of which are in the origin) is shown in Fig. 9. The washout filter significantly affects the acceleration amplitude below $1 \mathrm{~Hz}$, i.e., in the frequency band that is mostly relevant for flight mechanics. Indeed, it is well known that PIO events may not realistically be produced in general-purpose flight simulators $[36,37]$. However, the washout filter does not affect the amplitude of accelerations between 1 and $8 \mathrm{~Hz}$, which is mostly relevant for PAO. Only the phase is mildly affected.

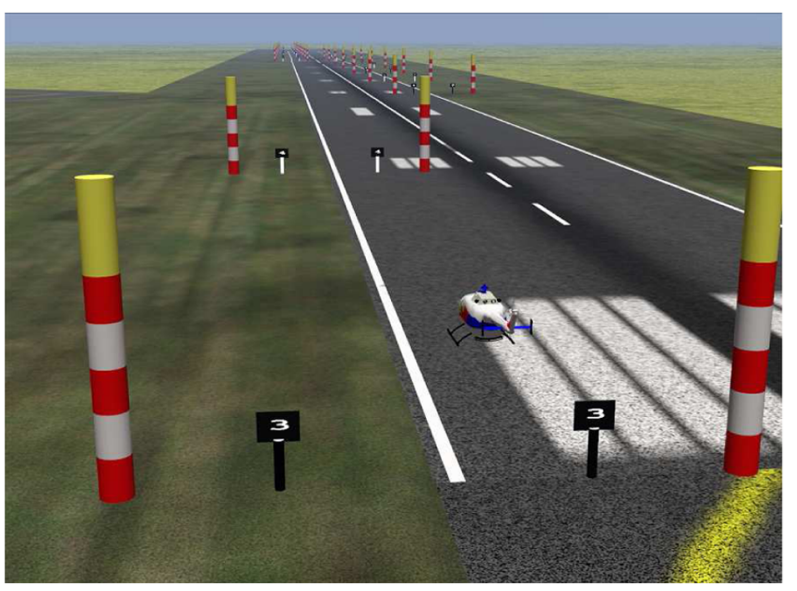

a) Course layout for roll step maneuver

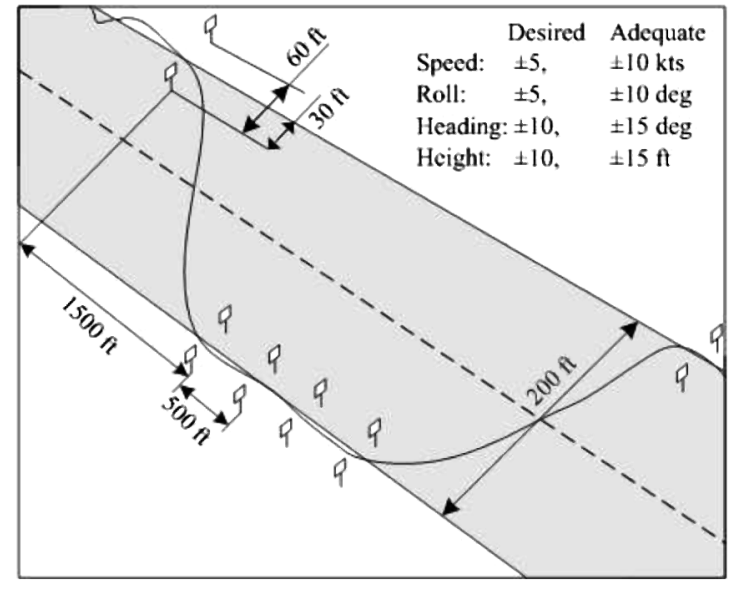

b) Test course and performance requirements

Fig. 10 Roll step maneuver description. 
Table 5 Configurations tested with roll step

\begin{tabular}{lccccc}
\hline \hline Case no. & Pilot no. & ASE/RB & Gain $G_{Y}$ & $\begin{array}{c}\text { Time } \\
\text { delay } \tau_{Y}, \text { ms }\end{array}$ & $\begin{array}{c}\text { Corresponding } \\
\text { Table 4 case }\end{array}$ \\
\hline A & 1,2 & ASE & 1.0 & 0.0 & 2 \\
B & 1,2 & ASE & 2.5 & 0.0 & 5 \\
C & 1,2 & ASE & 2.5 & 100.0 & 8 \\
D & 1,2 & ASE & 3.0 & 100.0 & 8 , increased $G_{Y}$ \\
E & 1,2 & RB & 3.0 & 100.0 & 8 , increased $G_{Y}$ \\
\hline \hline
\end{tabular}

In fact, the washout filter generates a lead effect in the involuntary pilot control frequency band, reducing the effective time delay between the inceptor motion and the actuator motion in the helicopter model simulated using HELIFLIGHT I. This effect can be easily estimated. For example, at the frequency of the predicted PAO instability of about $2.3 \mathrm{~Hz}$ (test pilot 1, case 5; Fig. 6d), with a phase angle of about $20 \mathrm{deg}$, the lead effect is

$$
\tau_{\text {lead }}=-\left.\frac{\angle H_{\mathrm{WO}}(j \omega)}{\omega}\right|_{\omega=2.3 \mathrm{~Hz}} \simeq-24 \mathrm{~ms}
$$

and the effective time delay experienced by the flight-simulator model, for a nominal value $\tau_{Y}=100 \mathrm{~ms}$, is
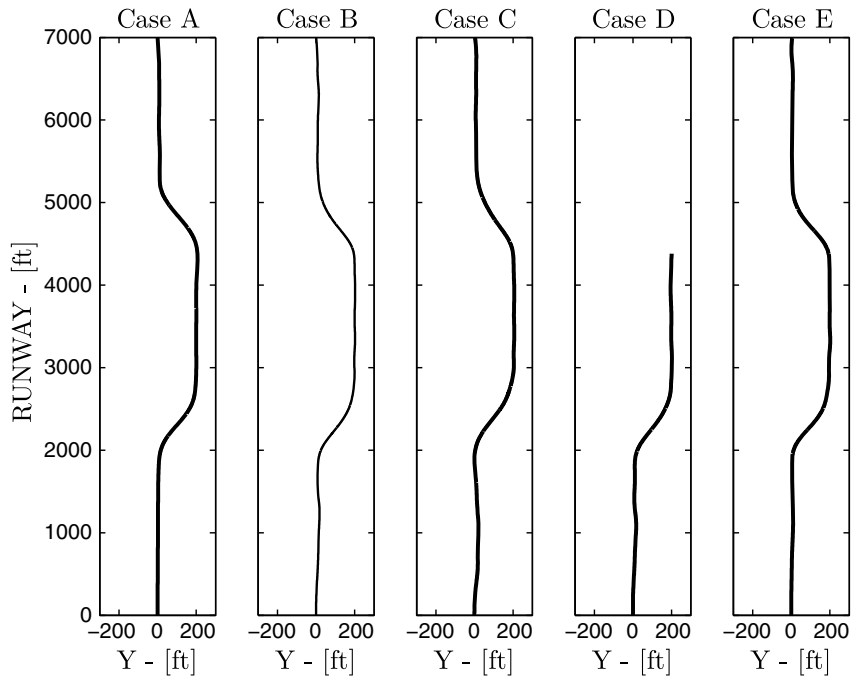

a) Trajectory - test pilot 1

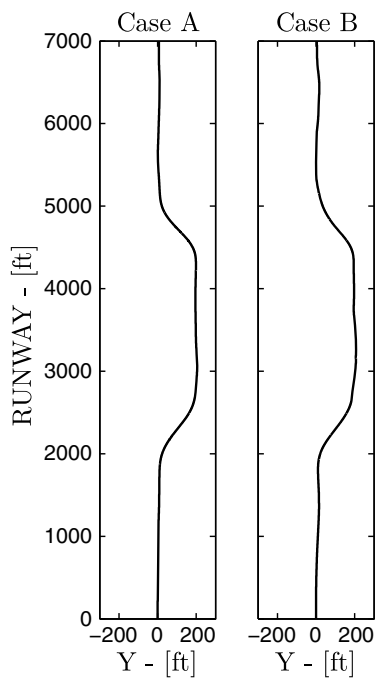

c) Trajectory - test pilot 2
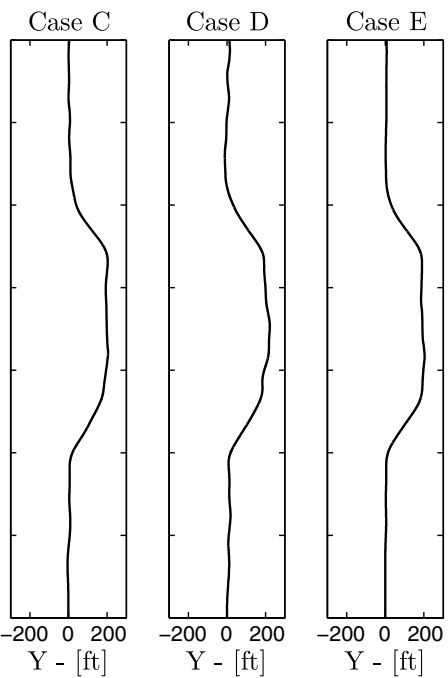

$$
\tau_{e}=\tau_{Y}+\tau_{\text {sim }}-\tau_{\text {lead }}=100 \mathrm{~ms}+70 \mathrm{~ms}-24 \mathrm{~ms}=146 \mathrm{~ms}
$$

which is a value that is close to the nominal value of $140 \mathrm{~ms}$ used for $\tau_{Y}$ in predictions. For this reason, a nominal time delay of $\tau_{Y}=100 \mathrm{~ms}$ is considered in the tests.

\section{A. FLIGHTLAB Implementation}

The linearized state-space models of the IAR330 and of the $\mathrm{BO} 105$, in forward flight at $80 \mathrm{kt}$, were loaded into the simulation environment using FLIGHTLAB. Aeroservoelastic (ASE) and rigidbody models have been used in the piloted flight-simulation tests. The rationale was to check whether RPC phenomena occurring with the ASE models can be reproduced using the equivalent RB models, to confirm (or otherwise) the aeroelastic nature of the encountered phenomena.

The input channels include the four pilot controls and a lateral external force applied at the helicopter CM. The latter represents a disturbance, intended to excite the pilot biodynamics.

The time history of the generic external force was generated by filtering a Gaussian white noise. The filter was designed to excite the pilot dynamics up to $10 \mathrm{~Hz}$. The standard deviation of the excitation could be modified with a gain for each channel during the piloted flight-simulation tests.

The pilot controls are modeled as being directly connected to the main and tail rotor collective and cyclic pitch angles. The control
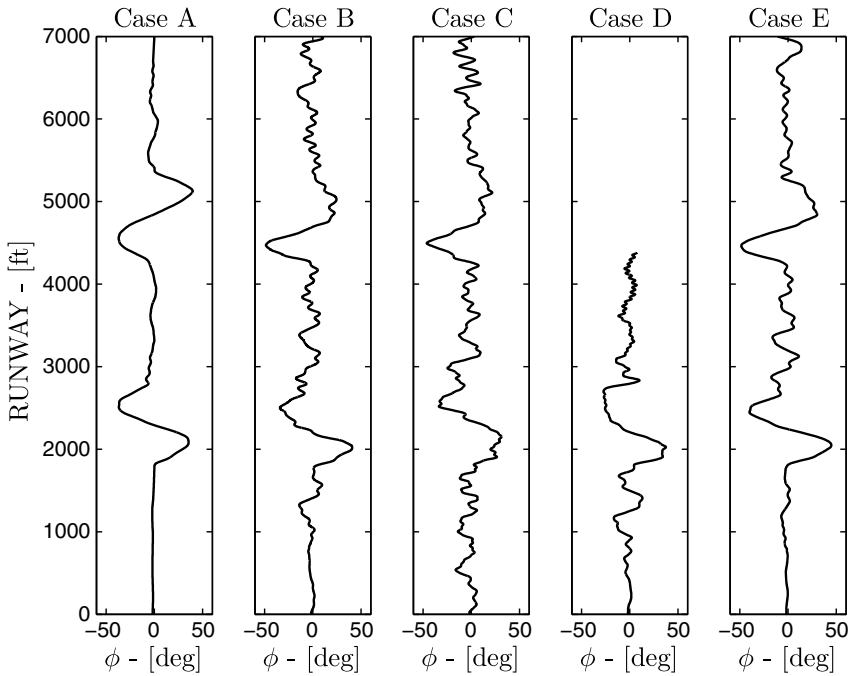

b) Bank angle - test pilot 1
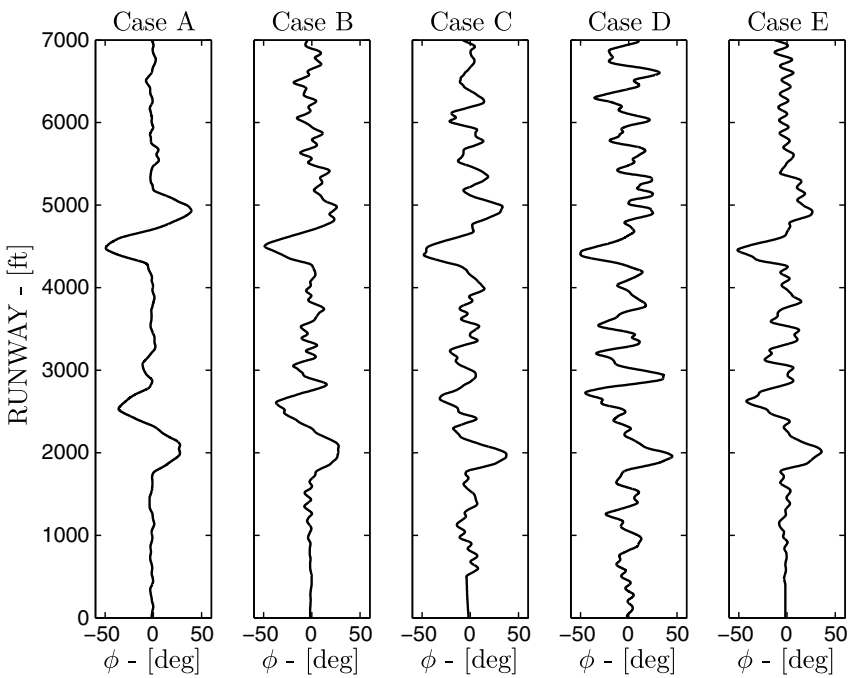

d) Bank angle - test pilot 2

Fig. 11 Trajectories and bank angles with regard to position along runway. 
gearing ratios have been introduced in the FLIGHTLAB models to convert the displacements of the control inceptors to collective and cyclic pitch angles. Moreover, each control gearing ratio has been augmented by introducing a configurable transport delay term to simulate the time delay between the control inceptor displacement and the corresponding rotor control due to a fly-by-wire control system.

Similarly, a standard set of output channels were defined. Output measurements were used to drive the motion platform control system
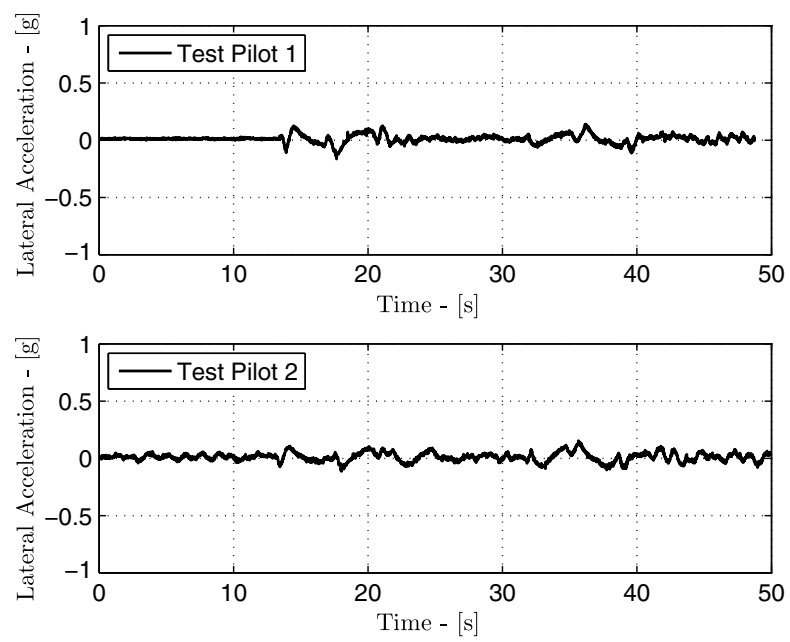

a) Case A: lateral acceleration
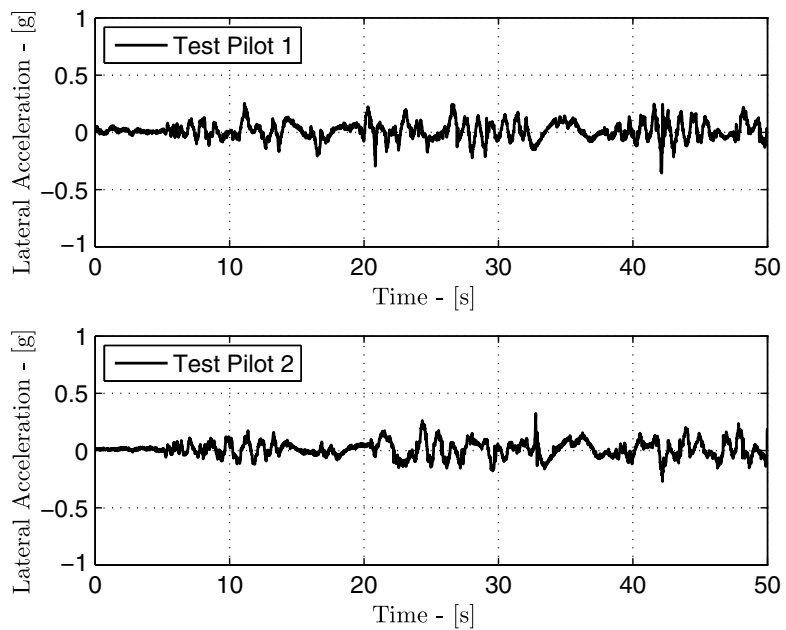

c) Case B: lateral acceleration
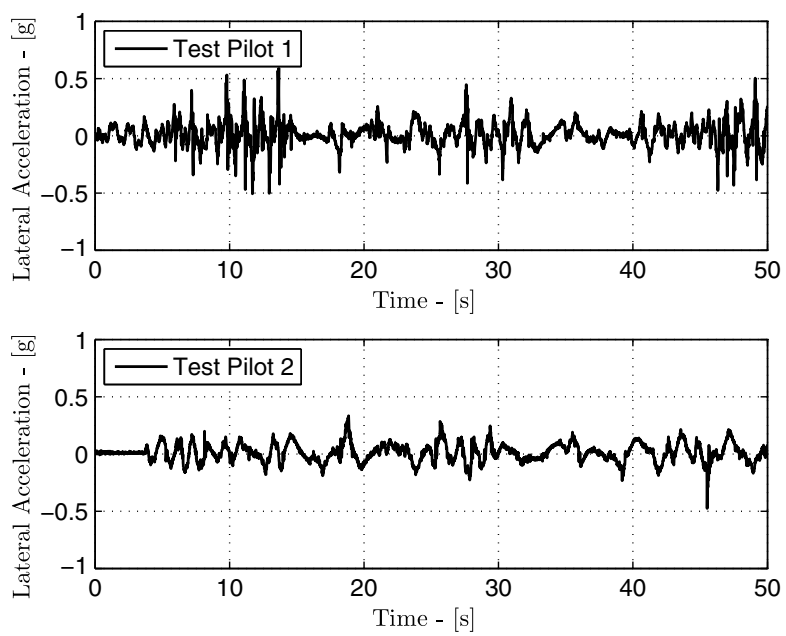

e) Case C: lateral acceleration and the external world visualization. In general, motion outputs have been measured at the vehicle model CM and at the pilot seat. CM displacements have been used to drive the external world visualization, whereas pilot seat accelerations and rates have been used to drive the simulator motion base.

Output measures were also used to drive the display instruments that are presented to the pilots during the piloted flight simulation. Speed, attitude and heading indicators, altimeter, and vertical speed indicator were also active.
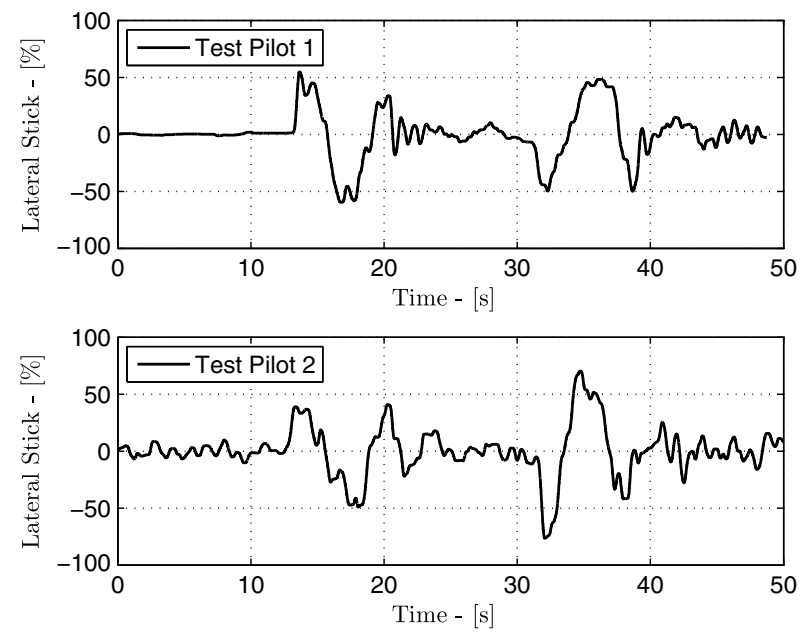

b) Case A: lateral stick
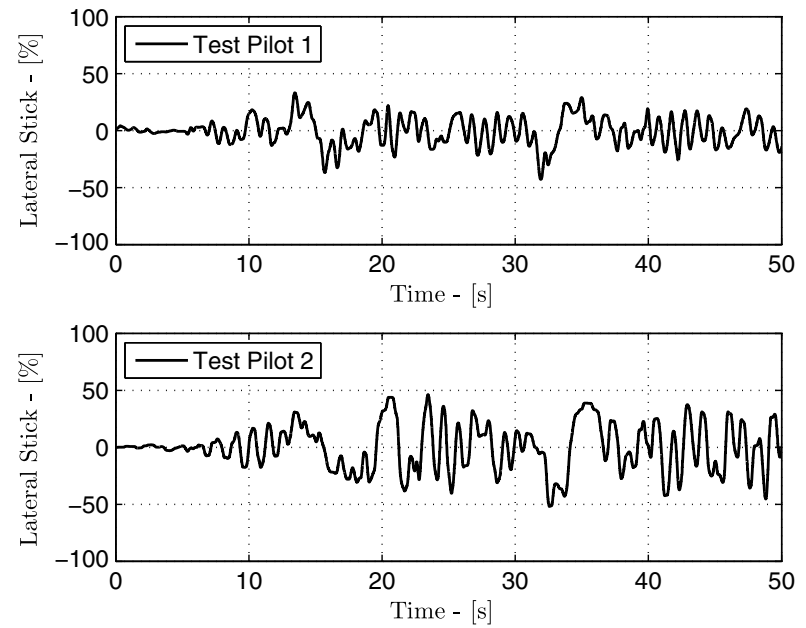

d) Case B: lateral stick
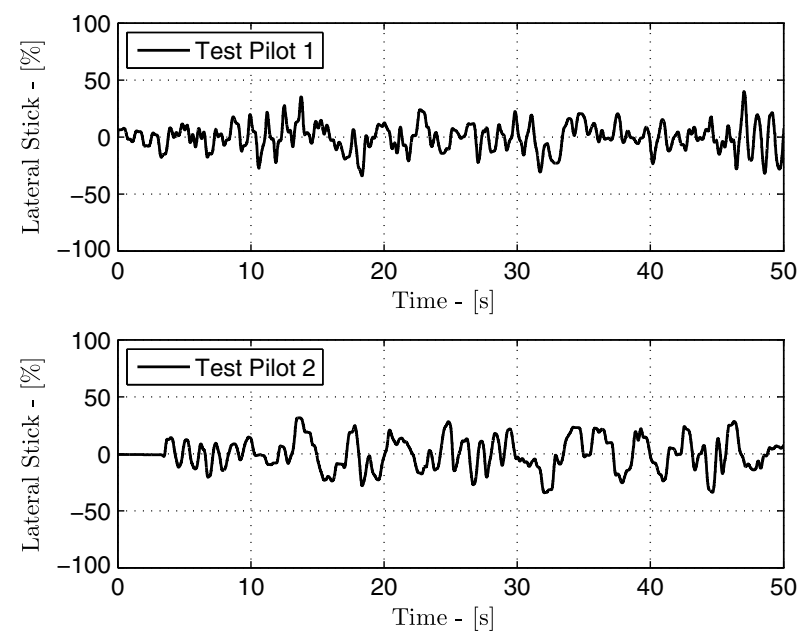

f) Case C: lateral stick

Fig. 12 BO105: time histories of lateral acceleration $a_{Y}$ and stick displacement $\delta_{Y}$. 
Each state-space model is a multi-input/multi-output model, with 7 input and 30 output signals.

\section{B. Pilot Task Description}

The roll step (RS) maneuver was selected to trigger the roll/lateral PAO instability with the test pilots flying the HELIFLIGHT I simulator. The RS, developed at the UOL for tiltrotor handling qualities evaluation, and subsequently adapted to helicopters [38], is shown in Fig. 10. It is a modified slalom maneuver (from [25]) that is designed to check both the vehicle's ability to maneuver in forward flight and the coordination required to perform the task. Furthermore, it is designed to trigger any objectionable interaxis couplings that might be present.

Task performance is forced through the use of "gates" positioned in the visual environment. The pilot must translate through predetermined gates, in a distance close to the width of a transport aircraft runway (approximately $200 \mathrm{ft}$ ). The aggression of the task can be defined through either changes to the aircraft flight speed or the longitudinal positioning of the gates along the runway. In this work, the maneuver was tested only at $80 \mathrm{kt}$ because the pilots considered it too demanding at higher speeds.

The course layout for the RS maneuver is shown in Fig. 10a. The aircraft is released in a trimmed flight condition along the left-hand edge of the runway, at the desired speed. The pilot is required to complete two translations across the runway (left to right, followed by right to left) with two periods of stabilization along the opposite edge of the runway: one after each runway translation. Further details of the course layout are discussed in [38].

The pilot was tasked with meeting the "desired" positional and speed tolerances (indicated in Fig. 10b) throughout the maneuver. However, the need of the pilots to stay within desirable, or at least "adequate," performance requirements was not emphasized, as the piloted flight simulations were not specifically intended to evaluate aircraft handling qualities.

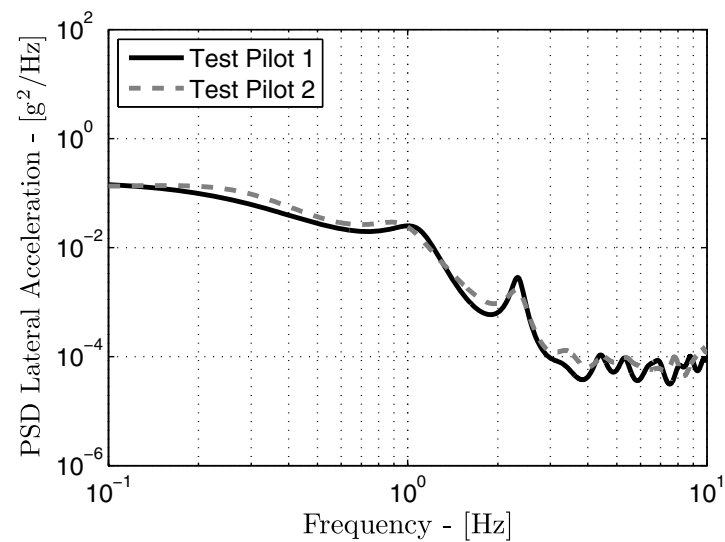

a) Case A: lateral acceleration
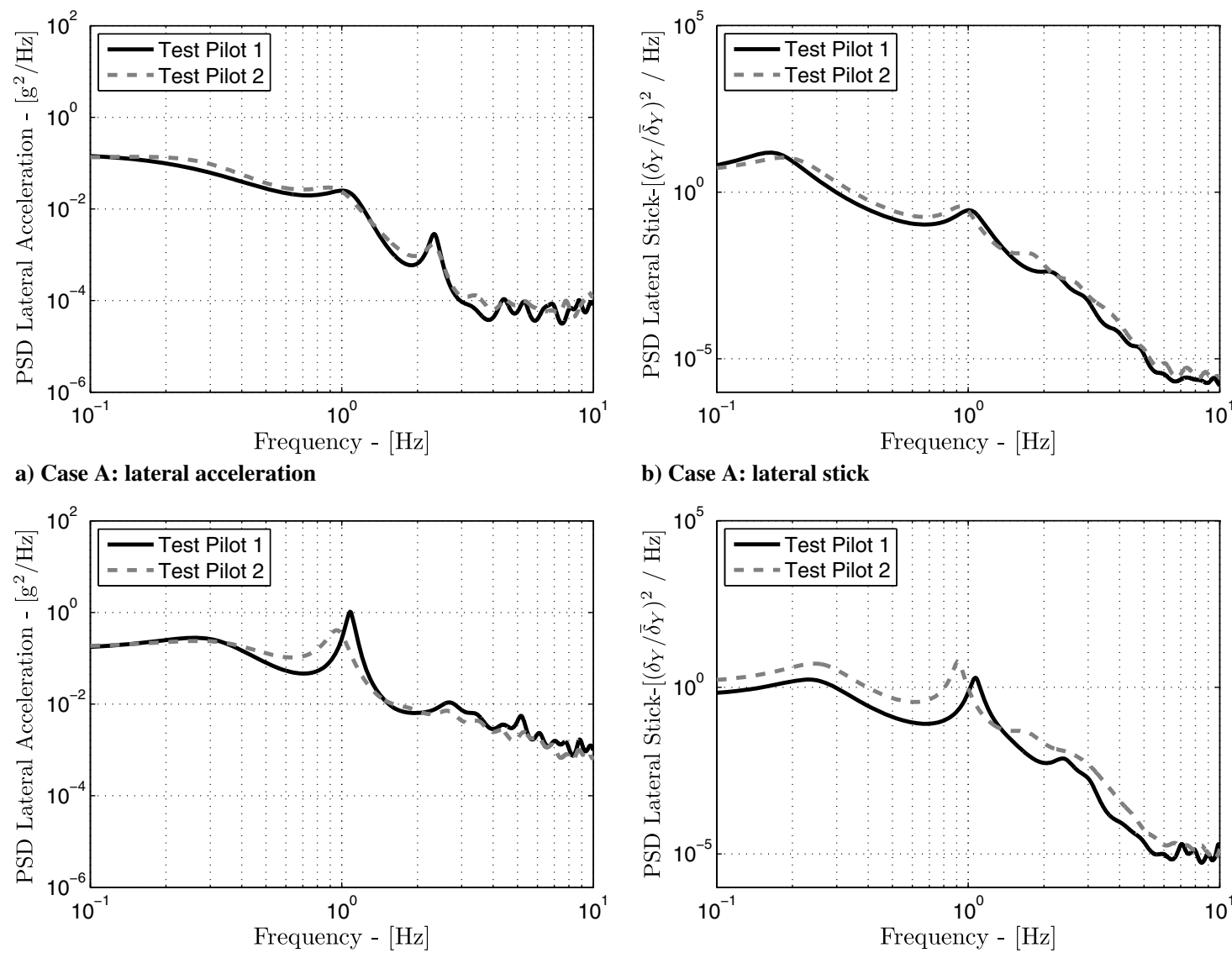

c) Case B: lateral acceleration

b) Case A: lateral stick

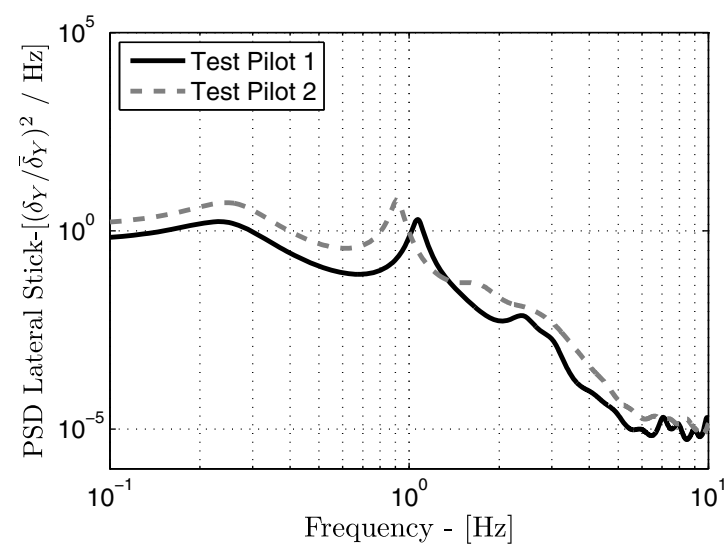

d) Case B: lateral stick

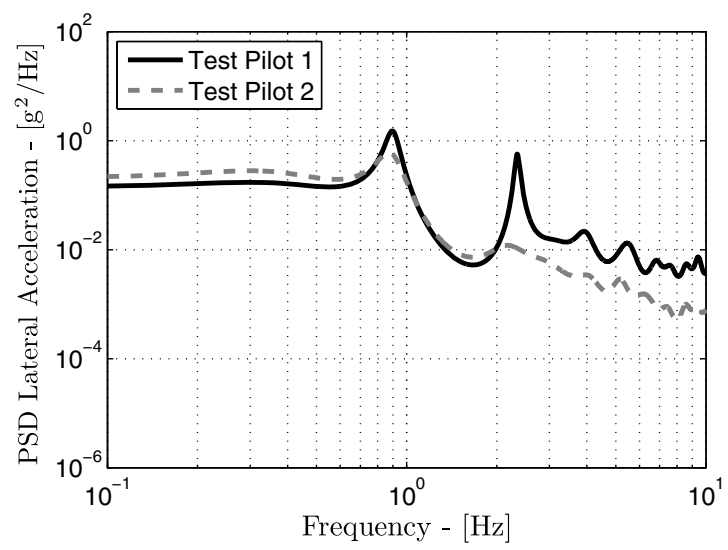

e) Case C: lateral acceleration

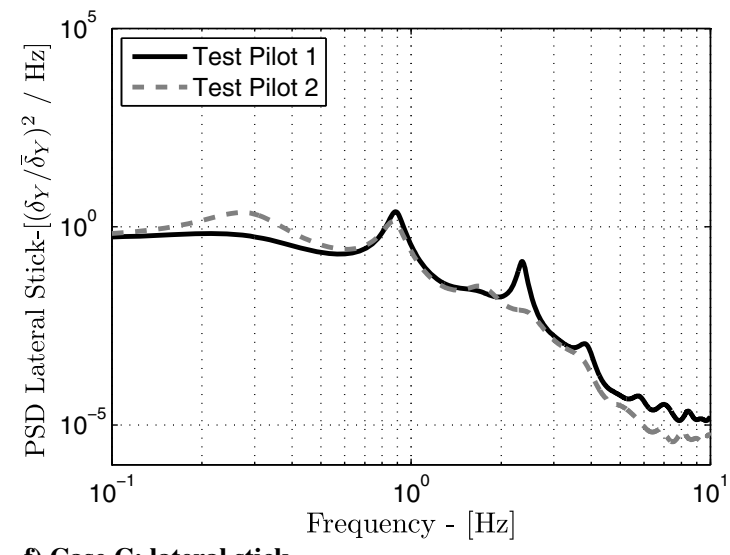

f) Case C: lateral stick

Fig. 13 BO105: PSD of lateral acceleration, $\Phi_{a_{Y}}(\omega)$, and stick displacement, $\Phi_{\delta_{Y}}(\omega)$. 
Due to the nature of the task, the RS was reportedly completed using "external" cueing only, which includes visual and acceleration cues along and about all axes. Pilots had no time to look inside the aircraft to determine their performance. Therefore, an element such as speed (which is not readily provided through external cueing) was difficult to maintain.

The RS maneuver forces the transition of the pilot's voluntary action from a mode characterized by feedforward (when the task is to perform two turns in sequence to line up from one side of the runway to the other) to a mode characterized by pure regulatory behavior (the "capture" phase, when the task is to bring the aircraft back to straight level flight, meeting strict performance requirements). The switch in the pilot's behavioral model may trigger a PIO.

\section{Influence of Pilot/Lateral Stick Control Feedback in Forward Flight}

During the testing, PAO occurrences were observed with test pilot 1. This pilot was predicted to be the most prone to this type of PAO. The RS maneuver, performed with the aeroservoelastic BO105 at $80 \mathrm{kt}$, confirms the PAO instability to be the result of an aeromechanical instability (similar to air resonance) created by the lightly damped main rotor regressive lead-lag mode at $2.28 \mathrm{~Hz}$, coupled with the pilot biodynamics/lateral stick dynamics.

The five configurations tested using the BO105 model are reported in Table $\underline{5}$. The piloted flight-simulation tests were performed using different control gearing ratios and time delays on the lateral cyclic control. The tests were conducted with pilots 1 and 2 flying the
BO105 in order to compare the different biodynamic responses and to verify the predictions. Test pilot 3 was unavailable at the time the piloted flight-simulation tests were performed. Trajectories and bank angles are reported in Fig. 11. The strongest roll/lateral PAO instability was triggered by test pilot 1 during test case $\mathrm{D}$. Only in this case was the pilot ever unable to complete the task, releasing the stick before the required runway transition from right to left. The bank angle of case D (Fig. 11b) also shows the high-frequency oscillations, related to $\mathrm{PAO}$, triggered by test pilot 1 's involuntary control action during the execution of the task.

Some time histories and power spectral densities (PSD) of the test cases corresponding to the configurations presented in Table $\underline{5}$ are shown. Figures 12 and 13 refer to cases A, B, and C; Figs. 13 and 14 refer to cases $\mathrm{D}$ and $\mathrm{E}$. The PSD of the lateral acceleration measured at the flight-simulator pod $\Phi_{a_{Y}}(\omega)$ has been reported with the PSD of the lateral cyclic control inceptor displacement related to the lateral stick $\Phi_{\delta_{Y}}(\omega)$.

In case A, the gear ratio is nominal and no time delay is present on the lateral cyclic control. The ASE model is used. The PSD of the pilot controls (Fig. 13b) shows that the activity of the two pilots on the lateral cyclic is quite similar and essentially confined to below $1 \mathrm{~Hz}$. The biodynamics of the pilots are not excited, and no PAO phenomena occur.

In case $\mathrm{B}$, the gearing ratio on the lateral cyclic control is 2.5 times the nominal value. The pilots are still able to complete the task, even though a PIO phenomenon occurs about the roll axis. The increased activity at $1 \mathrm{~Hz}$ (slightly above and with a more pronounced peak for
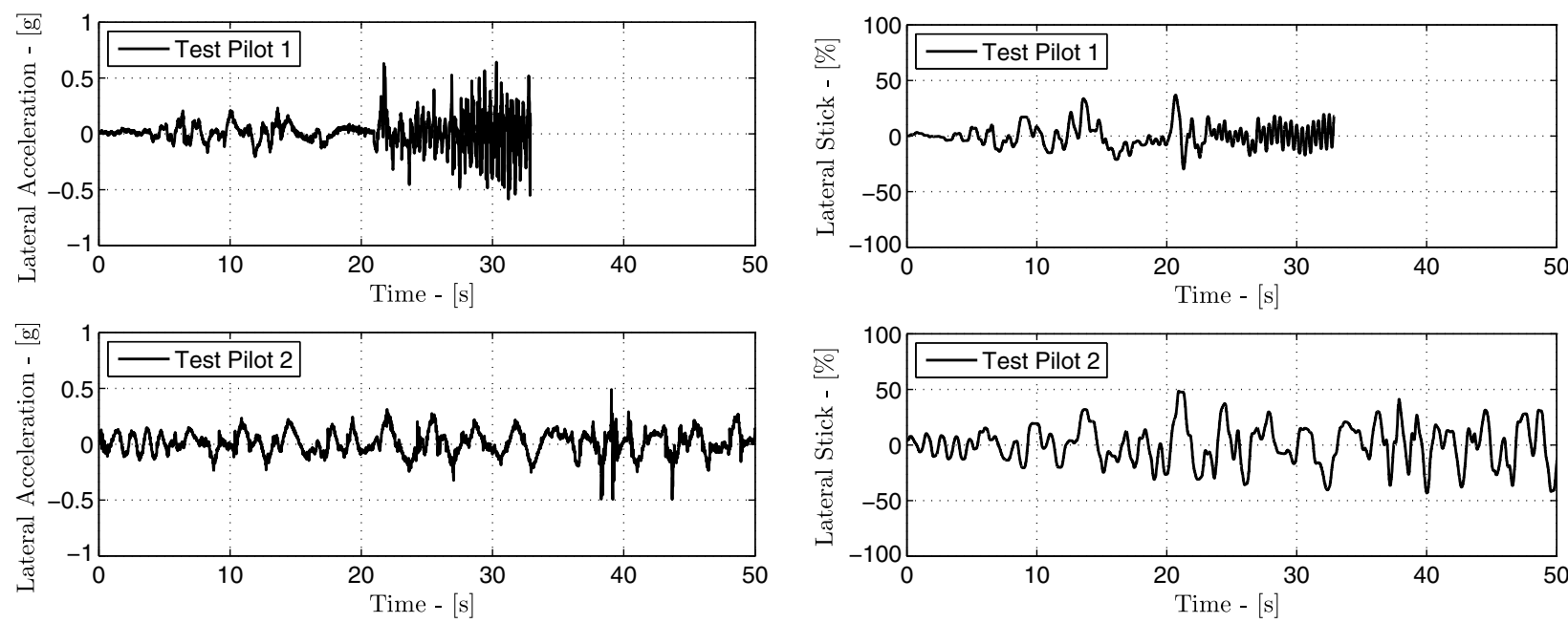

a) Case D (ASE): lateral acceleration
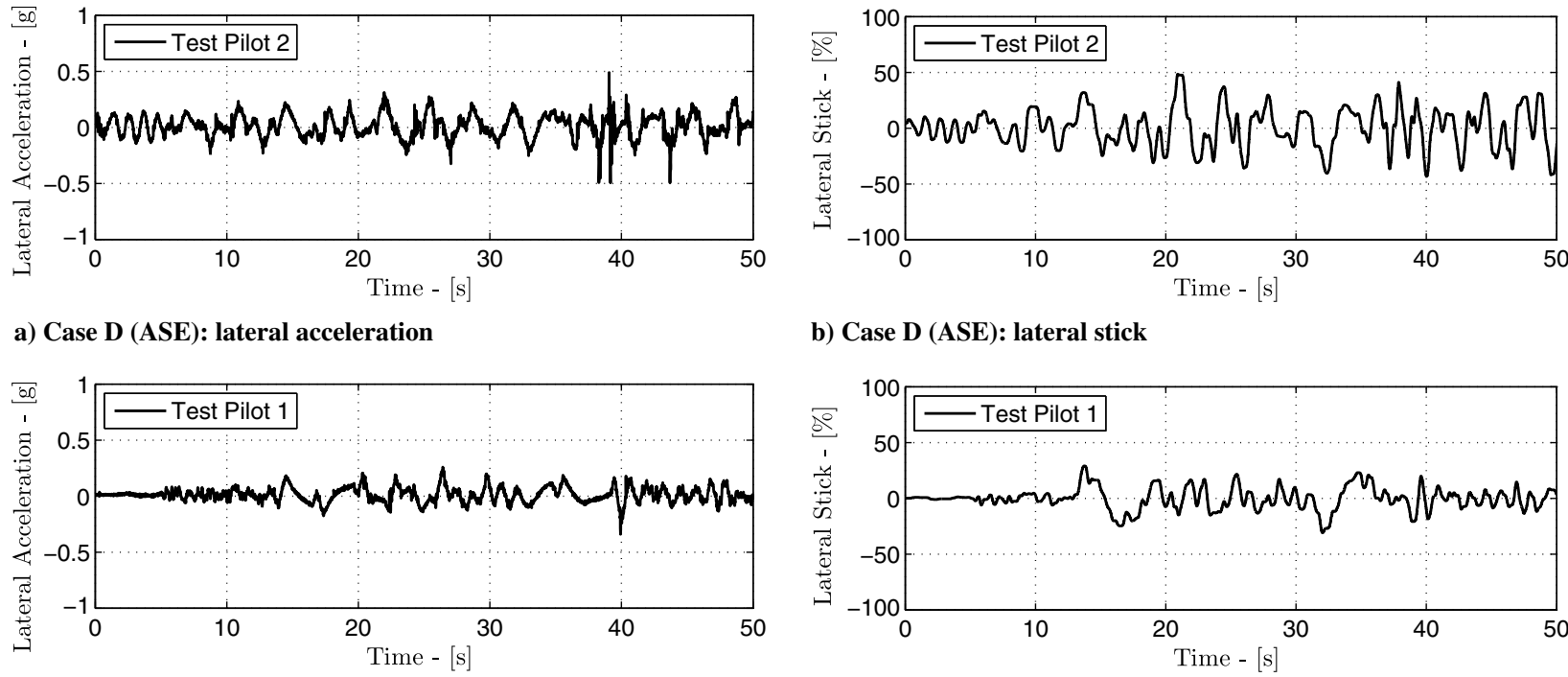

b) Case D (ASE): lateral stick
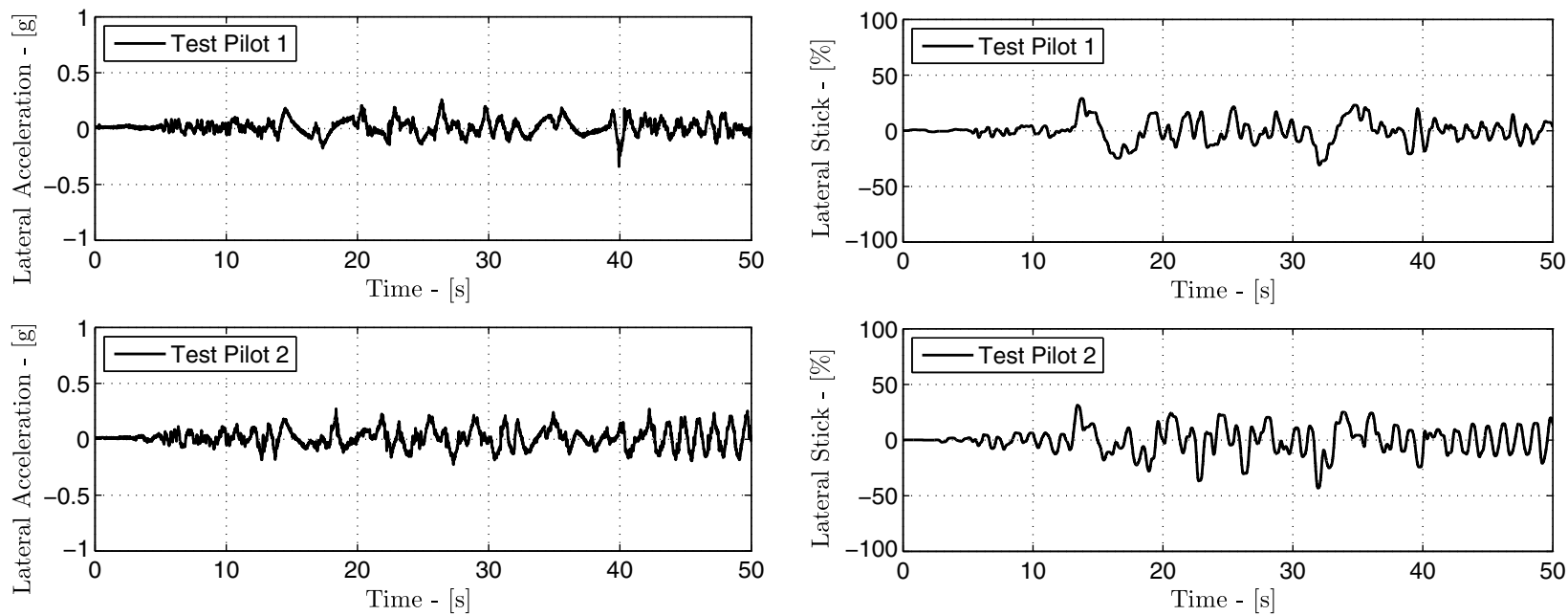

c) Case $\mathbf{E}(\mathrm{RB})$ : lateral acceleration

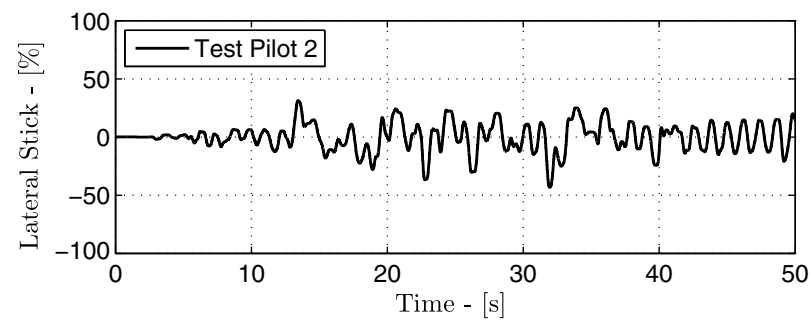

d) Case E (RB): lateral stick

Fig. 14 BO105: time histories of lateral acceleration $a_{Y}$ and stick displacement $\delta_{Y}$. 
pilot 1 , whereas slightly below and with a much less pronounced peak for pilot 2) (Fig. 13d) is related to the control activity employed by the pilots to stabilize the vehicle in the presence of the PIO instability. No PAO phenomenon, related to involuntary pilot biodynamics, was recorded.

In case $\mathrm{C}$, a $100 \mathrm{~ms}$ nominal time delay on the lateral cyclic control was used in addition to the increased gearing ratio of case $\mathrm{B}$. Considerable activity is still observed for both pilots slightly below $1 \mathrm{~Hz}$; contrary to the previous case, now, the peaks of the two pilots are almost coincident. The curve of pilot 1 also shows significant vibrations at the frequency of the poorly damped first lead-lag regressive mode of the main rotor (Fig. 13e). These vibrations are fed through the control inceptor as the involuntary biomechanical feedback related to pilot 1 (Fig. 13f). Pilot 2 does not show a similar behavior around $2 \mathrm{~Hz}$, either in the lateral acceleration or in the control inceptor motion. This case provides evidence that it is the time delay that is the key factor that causes the pilot response to be in phase opposition with the helicopter dynamics.

It is interesting to note that pilot 2 in cases $\mathrm{B}$ and $\mathrm{C}$ produces a voluntary control action peak at the same frequency, which is slightly below $1 \mathrm{~Hz}$. On the contrary, the peak voluntary activity of pilot 1 moves from above $1 \mathrm{~Hz}$ in case $\mathrm{B}$ to below $1 \mathrm{~Hz}$ in case $\mathrm{C}$, in which the PAO event occurs. The frequency shift of the peak voluntary action power with increased gearing ratio $G_{Y}$ seems to indicate a change in the cognitive behavior of the pilot, who becomes somewhat more "cautious." It is questionable whether such a behavior change is a consequence rather than the cause of PAO occurrence. Since the instability was predicted using biomechanical measurements performed in an open-loop control configuration (the involuntary pilot action was not causing the lateral acceleration of the flight-simulator pod), it is posited that the change in control strategy here is not the direct cause of the instability but, rather, is a consequence of it.

Since case $\mathbf{C}$ showed an incipient PAO instability as predicted for the configuration of case 5 , it was decided to assess this finding by testing a PVS configuration well beyond the stability limit. For this purpose, in case $\mathrm{D}$, a control gearing ratio larger than the one used in case $\mathrm{C}$ is considered (three times the nominal value). The nominal time delay of $100 \mathrm{~ms}$ has been maintained. This case is characterized by a strong PAO in the roll axis (Fig. 15b) for pilot 1 . The frequency slightly increases from 2.34 to $2.40 \mathrm{~Hz}$. When the PAO condition is reached, a divergent instability occurs and pilot 1 must abandon the task. As in the previous case, the biodynamics of pilot 2 are not excited and the PAO instability observed with pilot 1 does not occur with pilot 2. At low frequency, pilot 1 appears to apply less control action (the PSD of the stick motion is a measure of the control action as a function of the frequency) than in cases where no time delay is present, and the pilot definitely applies less control action than pilot 2 .

The configuration of case $E$ is the same as that of case $D$, in terms of flight-simulator setup, but the RB model has been used instead of the ASE one. In this case, no PAO phenomenon occurs (Fig. 15d) with either pilot. The RB model does not contain elastic modes: specifically the lead-lag regressive mode of the main rotor. The pilot biodynamics are not excited, despite the use of the same gain and time delay as in the ASE case. It is interesting to note that, with the RB model, a PIO instability occurs with test pilot 2 . The PIO condition is reached at the end of the task, during the stabilization phase, and Fig. 16 shows the control stick displacement and the bank angle during the latter part of the task. The two measured signals are nearly in phase opposition, confirming the low-frequency oscillatory motion at $0.85 \mathrm{~Hz}$, suggesting the occurrence of a PIO. Conversely, test pilot 1 is not involved either in a PIO or in a PAO instability. This result confirms the aeroelastic nature of the PAO phenomenon observed in cases $\mathrm{C}$ and D.

The most critical cases have also been tested with the aeroservoelastic model of the IAR330 at $80 \mathrm{kt}$. The results of Fig. 17 show that the two test pilots were only involved in PIO phenomena, which is possibly related to the high workload. In fact, PIO occurs for both

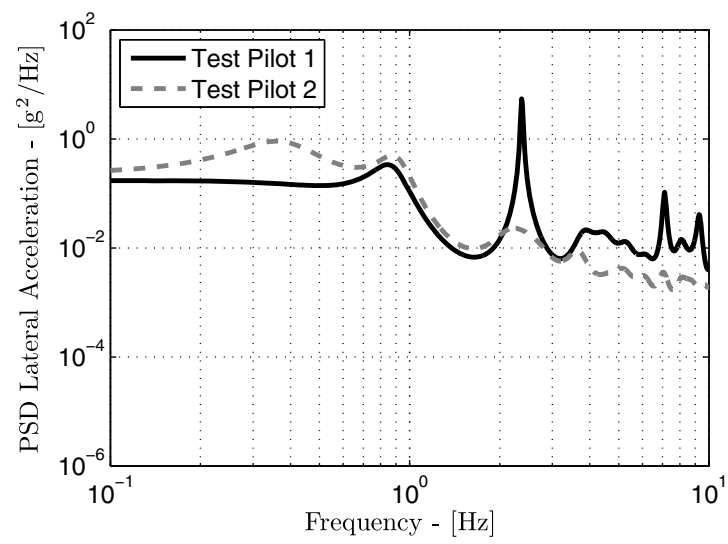

a) Case D (ASE): lateral acceleration

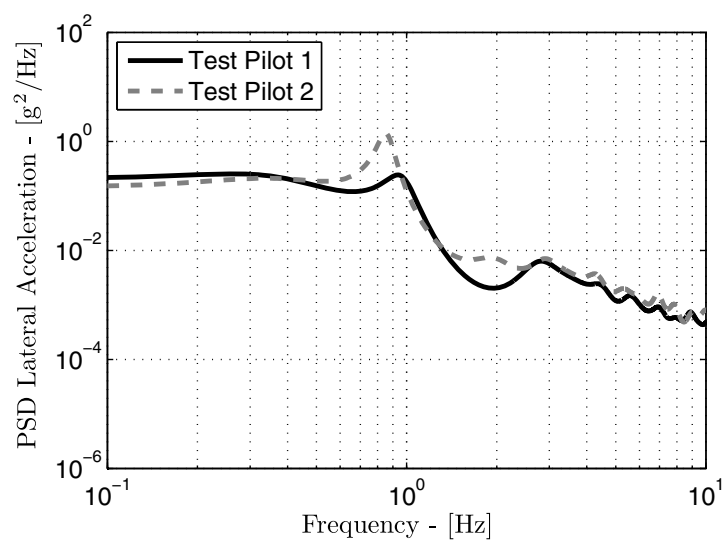

c) Case $\mathbf{E}(\mathbf{R B})$ : lateral acceleration

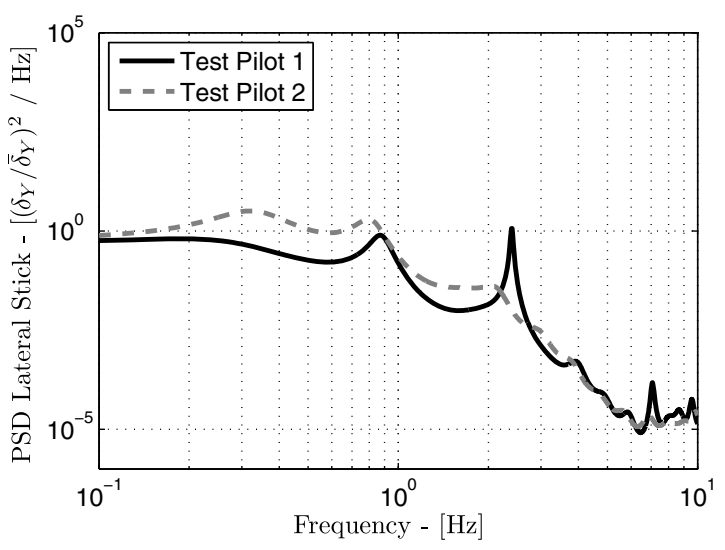

b) Case D (ASE): lateral stick

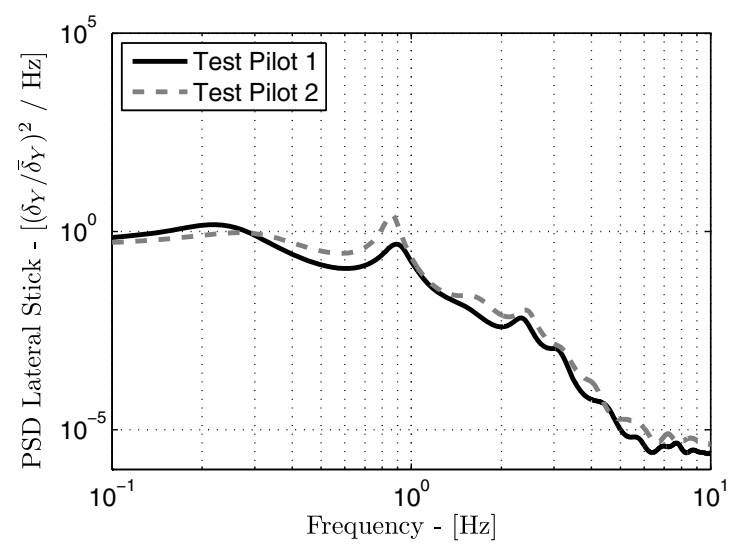

d) Case E (RB): lateral stick

Fig. 15 BO105: PSD of lateral acceleration, $\Phi_{a_{Y}}(\omega)$, and stick displacement, $\Phi_{\delta_{Y}}(\omega)$. 
vehicles at the top end of the rigid-body bandwidth (between 0.5 and $1 \mathrm{~Hz}$ ). The PSD of Fig. 15d shows considerable pilot activity for the BO105 (stick rotation) at that frequency, which can be interpreted as an indirect measure of workload; similar results can be observed in Fig. $17 \mathrm{~d}$ for the IAR330 with a large gearing ratio and time delay. The plots of Figs. $17 \mathrm{c}$ and $17 \mathrm{~d}$ indicate that the two pilots experienced a $\mathrm{PIO}$ at slightly different frequencies. The oscillations in the control inceptor during the capture phases of the RS can be clearly seen in the time histories of Fig. 17b. The pilots reported high workload ratings according to the Bedford scale [39], with high PIO ratings (PIOR)
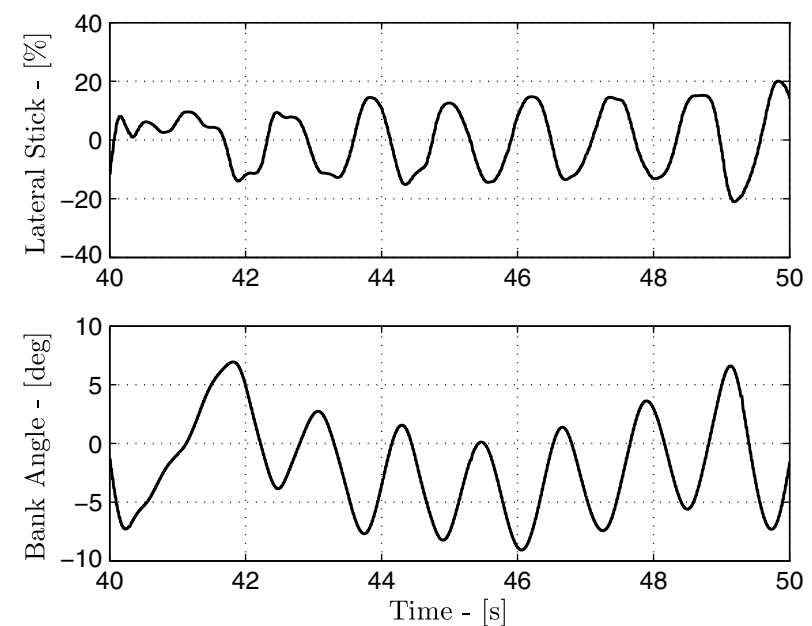

Fig. 16 BO105: lateral stick displacement $\delta_{Y}$ and bank angle $\varphi$; case E, pilot 2.
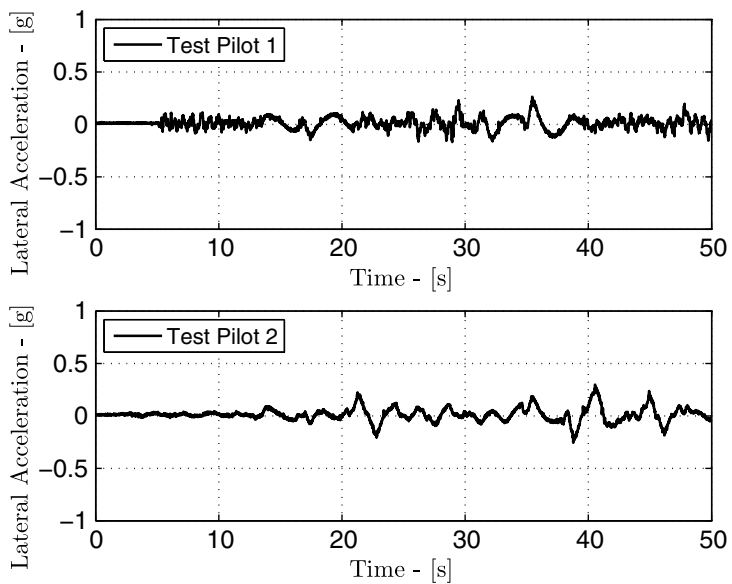

a) Case C: lateral acceleration (time histories)

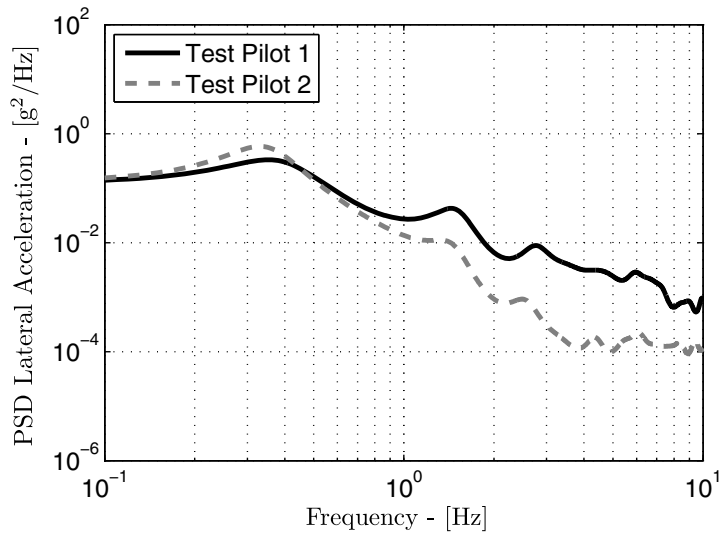

c) Case C: lateral acceleration (PSD)
Table 6 Predicted vs observed PAO

\begin{tabular}{lccccccc}
\hline \hline & & & \multicolumn{3}{c}{ Pilot 1} & \multicolumn{2}{c}{ Pilot 2} \\
\cline { 5 - 7 } \cline { 6 - 8 } Case no. & Gain & Delay, ms & $P$ & $O$ & & $P$ & $O$ \\
\hline & & IAR330 & & & & \\
2 & 1 & 0 & N & N & N & N \\
5 & 2.5 & 0 & N & N & N & N \\
8 & 2.5 & 140 & N & N & N & N \\
& & $B O 105$ & & & & \\
2 & 1 & 0 & N & N & N & N \\
5 & 2.5 & 0 & N & N & N & N \\
8 & 2.5 & 140 & Y & Y & N & N \\
\hline \hline
\end{tabular}

${ }^{\mathrm{a}} \mathrm{P}=$ predicted instability, $O=$ observed instability, $Y=$ yes, and $N=$ no.

according to the PIOR scale [40]. These considerations substantiate the notion that PIOs can be caused by high workload.

Table 6 summarizes the predicted and the tested configurations. The table highlights that the tests for configurations that were predicted to be unstable did actually result in an observed PAO instability. Pilot 3 participated in the biomechanical characterization, but unfortunately could not participate to the piloted flight-simulation tests. Predictions were made also for the hover case; of course, such predictions could not be tested using the roll step maneuver. Nonetheless, the models obtained from linearization about the hover have been used for different tests (specifically, lateral reposition according to [25] and other very low speed tasks); they did not show any appreciable tendency to PAO. The table refers to the ASE models; as already mentioned (Table 5), with the rigid-body RB models, no PAO was predicted nor observed, although pilot 2 experienced PIO (around $0.8 \mathrm{~Hz}$ ) using the parameters of case 8 with the BO105 model. Case 8 with the BO105 was predicted to be marginally stable
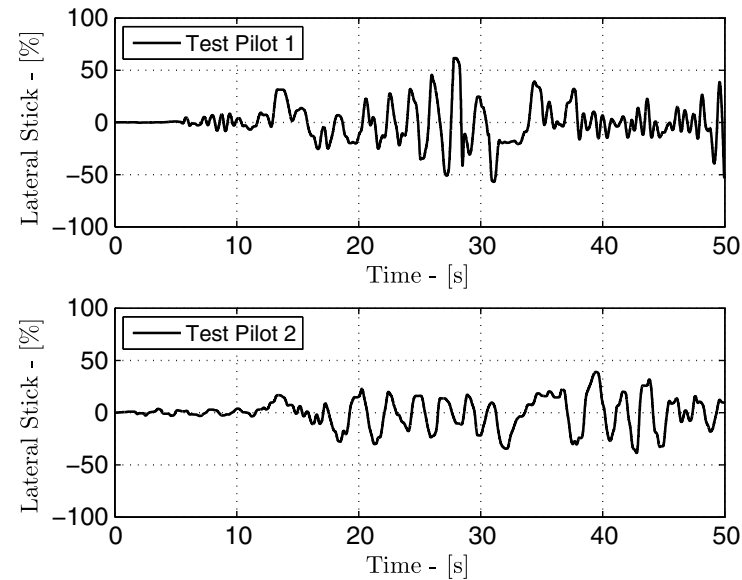

b) Case C: lateral stick (time histories)

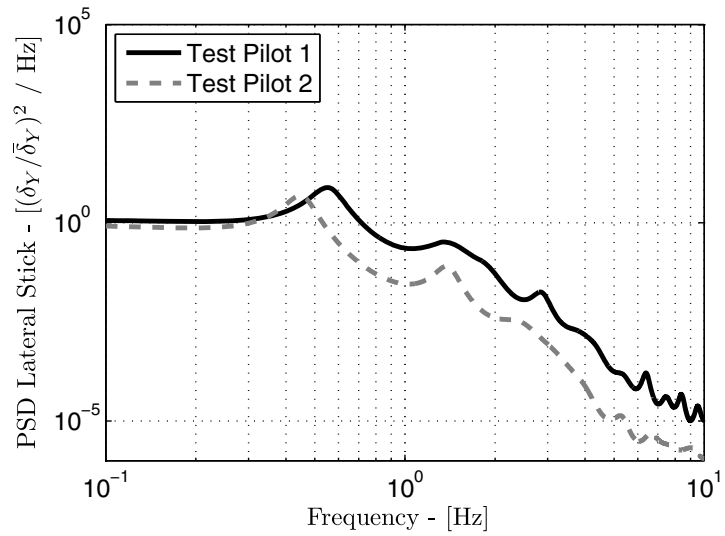

d) Case C: lateral stick (PSD)

Fig. 17 IAR330: lateral acceleration $a_{Y}$ and stick displacement $\delta_{Y}$ for test case $\mathrm{C}$. 
with pilot 1 (Fig. 6d). The case was repeated for pilots 1 and 2 with the gain set to 3.0 , to confirm the observed PAO with pilot 1 and to confirm its absence with pilot 2 . The results were consistent with the predictions for case 8 . In conclusion, the table shows that observations always confirmed predictions. This result indicates that PAO onset can be predicted using linear aeroservoelastic models and identified pilot biomechanics transfer functions.

\section{Conclusions}

In response to a perceived absence of tools and techniques to predict pilot-assisted oscillation phenomena early in the design process, linear aeroelastic models have been coupled to pilot biodynamic models, derived from simulator experimental excitation, to predict configurations and flight conditions that will result in either PAO events being triggered or not. Two aeroelastic helicopter configurations were used: a light helicopter with a hingeless rotor and a medium helicopter with an articulated rotor. Similarly, three pilot models, derived from pilots with various anthropometric characteristics were used. The work reported in this paper specifically investigated the roll/lateral PAO phenomena of helicopters.

From this new technique, the following can be concluded: pilotvehicle configurations are vulnerable to PAO phenomena when the pilot's biodynamic poles are located close to a structural/rotor frequency that can be excited by the relevant inceptor input and/or vehicle motion. For example, the numerical linear BO105 aeroelastic model was shown to be vulnerable to roll/lateral PAO phenomena, whereas the linear IAR330 aeroelastic model was not. This was due to the pilot's biodynamic poles and the BO105's main rotor first regressive lead-lag mode being located close to one other. This resulted in a reduction of the available phase margin, becoming negative when sufficient time delay was introduced into the lateral control path. The use of linear aeroelastic vehicle models with identified biodynamic pilot models in the control feedback loop proved to be an excellent predictor for the results obtained from the experimental simulator flight trials ( $100 \%$ correct). For the BO105 configurations, as per the predictions, a PAO instability was driven by test pilot 1 with a gearing ratio 2.5 times the nominal value and with a $100 \mathrm{~ms}$ time delay on the lateral cyclic control, although the pilot was still able to complete the task. Increasing the gearing ratio to three times the nominal value while maintaining the same time delay, test pilot 1 triggered a strong PAO and had to abandon the task. Conversely (but again, as per the predictions), test pilot 2 did not become involved in a PAO. Similarly, for the IAR330 model configurations, no PAO phenomena were predicted to occur and none were observed in the experimental simulation flight trials. This is because the IAR330 lead-lag regressive mode is placed far away from the pilots' biodynamic poles and shows considerable damping. The anthropometric and flying characteristics of the prospective pilot population needs to be taken into account by designers when considering PAO. In this study, test pilot 1 was found to be the only pilot predicted and observed to drive the coupled system to be unstable. This pilot was characterized by a low biomechanical natural frequency and a high gain. As a consequence, the phase margin of the resulting pilotvehicle system was reduced in a manner not observed with the other pilots used. Models of the BO105 containing only the rigid-body modes of motions were not able to predict PAO, since they did not contain the degrees of freedom required to destabilize the pilotvehicle system (i.e., the lead-lag regressive mode of the main rotor). The aeroelastic components of the model are therefore critical for this technique to be used successfully. The observed roll/lateral PAO instability can be eliminated by introducing viscous damping onto the in-plane main rotor modes. Overall, the use of the novel technique described in this paper will therefore be invaluable when used to identify PAO instabilities in current and future rotorcraft designs.

\section{Acknowledgment}

The research leading to these results has received funding from the European Community's Seventh Framework Programme (FP7/ 2007-2013) under grant agreement no. 266073.

\section{References}

[1] Harris, F. D., Kasper, E. D., and Iseler, L., "US Civil Rotorcraft Accidents: 1963 Through 1997,” NASA TM-2000-209597, Dec. 2000.

[2] Walden, R. B., "A Retrospective Survey of Pilot-Structural Coupling Instabilities in Naval Rotorcraft," American Helicopter Society 63rd Annual Forum, American Helicopter Soc. International, Alexandria, VA, May 2007, pp. 1783-1800.

[3] Mitchell, D. G., and Klyde, D. H., "Recommended Practices for Exposing Pilot-Induced Oscillations or Tendencies in the Development Process," USAF Developmental Test and Evaluation Summit, AIAA Paper 2004-6810, Nov. 2004, pp. 1-20.

[4] Dieterich, O., Götz, J., DangVu, B., Haverdings, H., Masarati, P., Pavel, M. D., Jump, M., and Gennaretti, M., "Adverse Rotorcraft-Pilot Coupling: Recent Research Activities in Europe," 34th European Rotorcraft Forum, Royal Aeronautical Soc., London, Sept. 2008, pp. 740-786.

[5] Jex, H. R., and Magdaleno, R. E., "Biomechanical Models for Vibration Feedthrough to Hands and Head for a Semisupine Pilot," Aviation, Space, and Environmental Medicine, Vol. 49, Nos. 1-2, 1978, pp. 304-316.

[6] Gabel, R., and Wilson, G. J., "Test Approaches to External Sling Load Instabilities," Journal of the American Helicopter Society, Vol. 13, No. 3, 1968, pp. 44-55. doi:10.4050/JAHS.13.44

[7] Bilger, J., Marr, R., and Zahedi, A., "Results of Structural Dynamic Testing of the XV-15 Tilt Rotor Research Aircraft," Journal of the American Helicopter Society, Vol. 27, No. 2, 1982, pp. 58-65. doi:10.4050/JAHS.27.58

[8] Parham, T. Jr., Popelka, D., Miller, D. G., and Froebel, A. T., "V-22 Pilot-in-the-loop Aeroelastic Stability Analysis," American Helicopter Society 47th Annual Forum, American Helicopter Soc., Phoenix, AZ, May 1991

[9] Pavel, M. D., Jump, M., Dang-Vu, B., Masarati, P., Gennaretti, M., Ionita, A., Zaichik, L., Smaili, H., Quaranta, G., Yilmaz, D., Jones, M., Serafini, J., and Malecki, J., "Adverse Rotorcraft Pilot Couplings-Past, Present and Future Challenges," Progress in Aerospace Sciences, Vol. 62, Oct. 2013, pp. 1-51. doi:10.1016/j.paerosci.2013.04.003

[10] Pavel, M. D., Malecki, J., DangVu, B., Masarati, P., Gennaretti, M., Jump, M., Jones, M., Smaili, H., Ionita, A., and Zaicek, L., "Present and Future Trends in Aircraft and Rotorcraft Pilot Couplings-a Retrospective Survey of Recent Research Activities within the European Project ARISTOTEL," 37th European Rotorcraft Forum, Paper 116, Gallarate, Italy, Sept. 2011.

[11] Pavel, M. D., Malecki, J., DangVu, B., Masarati, P., Gennaretti, M., Jump, M., Smaili, H., Ionita, A., and Zaicek, L., "A Retrospective Survey of Adverse Rotorcraft Pilot Couplings in European Perspective," American Helicopter Society 68th Annual Forum, Vol. 3, American Helicopter Soc. International, Alexandria, VA, May 2012, pp. 22382251.

[12] Gennaretti, M., Serafini, J., Masarati, P., and Quaranta, G., "Effects of Biodynamic Feedthrough in Rotorcraft-Pilot Coupling: Collective Bounce Case," Journal of Guidance, Control, and Dynamics, Vol. 36, No. 6, 2013, pp. 1709-1721. doi: $10.2514 / 1.61355$.

[13] Masarati, P., Quaranta, G., Lu, L., and Jump, M., "A Closed Loop Experiment of Collective Bounce Aeroelastic Rotorcraft-Pilot Coupling," Journal of Sound and Vibration, Vol. 333, No. 1, Jan. 2014, pp. 307-325, doi:10.1016/j.jsv.2013.09.020.

[14] Muscarello, V., Quaranta, G., and Masarati, P., "The Role of Rotor Coning in Helicopter Proneness to Collective Bounce," Aerospace Science and Technology, Vol. 36, July 2014, pp. 103-113. doi:10.1016/j.ast.2014.04.006

[15] Venrooij, J., Abbink, D. A., Mulder, M., van Paassen, M. M., and Mulder, M., "Biodynamic Feedthrough is Task Dependent," 2010 IEEE International Conference on Systems Man and Cybernetics (SMC), IEEE, Piscataway, NJ, Oct. 2010, pp. 2571-2578. doi:10.1109/ICSMC.2010.5641915.

[16] Masarati, P., Quaranta, G., and Jump, M., "Experimental and Numerical Helicopter Pilot Characterization for Aeroelastic Rotorcraft-Pilot Couplings Analysis," Journal of Aerospace Engineering, Vol. 227, No. 1, Jan. 2013, pp. 124-140. doi: $10.1177 / 0954410011427662$.

[17] Masarati, P., Muscarello, V., and Quaranta, G., "Linearized Aeroservoelastic Analysis of Rotary-Wing Aircraft," 36th European Rotorcraft Forum, Paris, Sept. 2010, Paper 99.

[18] Masarati, P., Muscarello, V., Quaranta, G., Locatelli, A., Mangone, D., Riviello, L., and Viganò, L., "An Integrated Environment for Helicopter Aeroservoelastic Analysis: the Ground Resonance Case," 37th European Rotorcraft Forum, Gallarate, Italy, Sept. 2011, Paper 177. 
[19] Craig, R. R. Jr., and Bampton, M. C. C., "Coupling of Substructures for Dynamic Analysis," AIAA Journal, Vol. 6, No. 7, July 1968, pp. 1313-1319. doi: $10.2514 / 3.4741$

[20] Bousman, W. G., Young, C., Toulmay, F., Gilbert, N. E., Strawn, R. C., Miller, J. V., Maier, T. H., Costes, M., and Beaumier, P., "A Comparison of Lifting-Line and CFD Methods with Flight Test Data from a Research Puma Helicopter," NASA TM-110421, Oct. 1996.

[21] Padfield, G. D., Helicopter Flight Dynamics: The Theory and Application of Flying Qualities and Simulation Modelling, Blackwell Publ., Boston, 2007, Chap. 4, Appendix A4.

[22] Stoppel, J., and Degener, M., "Investigations of Helicopter Structural Dynamics and a Comparison with Ground Vibration Tests," Journal of the American Helicopter Society, Vol. 27, No. 2, April 1982, pp. 34-42. doi:10.4050/JAHS.27.34.

[23] Cardani, C., and Mantegazza, P., "Continuation and Direct Solution of the Flutter Equation," Computers and Structures, Vol. 8, No. 2, 1976, pp. 185-192. doi:10.1016/0045-7949(78)90021-4.

[24] Kaletka, J., von Grünhagen, W., Tischler, M. B., and Fletcher, J. W., "Time and Frequency Domain Identification and Verification of BO105 Dynamic Models," 15th European Rotorcraft Forum, Amsterdam, Sept. 1989, Paper 66.

[25] Anon., "Performance Specification, Handling Qualities Requirements for Military Rotorcraft," U.S. Army Aviation and Missile Command, Aeronautical Design STD 33-E-PRF, Redstone Arsenal, AL, 2000.

[26] Battipede, M., Gili, P., Carano, L., and Vaccaro, V., "Constrained Notch Filter Optimization for a Fly-by-Wire Flight Control System," l'Aerotecnica Missili e Spazio, Vol. 88, No. 3, 2009, pp. 105-113.

[27] Pavel, M. D., "Modeling Lead-Lag Dynamics for Rotorcraft-PilotCouplings Investigation," American Helicopter Society 66th Annual Forum, Vol. 2, American Helicopter Soc. International, Alexandria, VA, May 2010, pp. 1699-1720.

[28] Allen, R. W., Jex, H. R., and Magdaleno, R. E., "Manual Control Performance and Dynamic Response During Sinusoidal Vibration," Aerospace Medical Research Lab. TR-73-78, Oct. 1973.

[29] Höhne, G., "Computer Aided Development of Biomechanical Pilot Models," Aerospace Science and Technology, Vol. 4, No. 1, Jan. 2000, pp. 57-69.

doi:10.1016/S1270-9638(00)00117-6.
[30] Mayo, J. R., "The Involuntary Participation of a Human Pilot in a Helicopter Collective Control Loop," 15th European Rotorcraft Forum, Amsterdam, Sept. 1989, Paper 81

[31] Padfield, G. D., and White, M. D., "Flight Simulation in Academia; HELIFLIGHT in Its First Year of Operation," The Aeronautical Journal of the Royal Aeronautical Society, Vol. 107, No. 1075, Sept. 2003, pp. 529-538.

[32] FLIGHTLAB Theory Manual, Vol. 1, Advanced Rotorcraft Technology, Mountain View, California, March 2004.

[33] Ljung, L., System Identification: Theory for the User, Prentice-Hall, Englewood Cliffs, NJ, 1987, Chap. 6.

[34] Hess, R. A., "Theory for Aircraft Handling Qualities Based Upon a Structural Pilot Model," Journal of Guidance, Control, and Dynamics, Vol. 12, No. 6, 1989, pp. 792-797. doi:10.2514/3.20483.

[35] Szabolcsi, R., "Modeling of the Human Pilot Time Delay Using Padé Series," Academic and Applied Research in Military Science, Vol. 6, No. 3, 2007, pp. 405-428.

[36] Ferguson, S. W., Clement, W. F., Cleveland, W. B., and Key, D. L., "Assessment of Simulation Fidelity Using Measurements of Piloting Technique in Flight," American Helicopter Society 40th Annual Forum, American Helicopter Soc. International, Alexandria, VA, May 1984, pp. 67-92.

[37] McRuer, D. T., Aviation Safety and Pilot Control: Understanding and Preventing Unfavourable Pilot-Vehicle Interactions, National Research Council, National Academy Press, Washington D.C., 1997.

[38] Cameron, N., and Padfield, G. D., "Handling Qualities Degradation in Tilt-Rotor Aircraft Following Flight Control System Failures," 30th European Rotorcraft Forum, Marseilles, France, Sept. 2004.

[39] Roscoe, A., and Ellis, G., "A Subjective Rating Scale for Assessing Pilot Workload in Flight: A Decade of Practical Use," Royal Aerospace Establishment TR-90019, 1990.

[40] Jones, M., Jump, M., Lu, L., Yilmaz, D., and Pavel, M. D., "Using the Phase-Aggression Criterion to Identify Rotorcraft Pilot Coupling Events," 38th European Rotorcraft Forum, Amsterdam, Sept. 2012.

D. Klyde Associate Editor 